\title{
Role of additives and surface passivation on the performance of perovskite solar cells
}

\author{
Samuel Abicho ${ }^{1} \cdot$ Bekele Hailegnaw $^{2} \cdot$ Getachew Adam Workneh $^{1}$ (D) Teketel Yohannes ${ }^{3}$
}

Received: 2 March 2021 / Accepted: 13 December 2021 / Published online: 27 December 2021

(c) The Author(s) 2021

\begin{abstract}
Outstanding improvement in power conversion efficiency (PCE) over 25\% in a very short period and promising research developments to reach the theoretical PCE limit of single junction solar cells, 33\%, enables organic-inorganic perovskite solar cells (OIPSCs) to gain much attention in the scientific and industrial community. The simplicity of production of OIPSCs from precursor solution either on rigid or flexible substrates makes them even more attractive for low-cost roll-to-roll production processes. Though OIPSCs show as such higher PCE with simple solution processing methods, there are still unresolved issues, while attempts are made to commercialize these solar cells. Among the major problems is the instability of the photoactive layer of OIPSCs at the interface of the charge transport layers and /or electrodes during prolonged exposure to moisture, heat and radiation. To achieve matched PCE and stability, several techniques such as molecular and interfacial engineering of components in OIPSCs have been applied. Moreover, in recent times, engineering on additives, solvents, surface passivation, and structural tuning have been developed to reduce defects and large grain boundaries from the surface and/or interface of organic-inorganic perovskite films. Under this review, we have shown recently developed additives and passivation strategies, which are strongly focused to enhance PCE and long-term stability simultaneously.
\end{abstract}

Keywords Organic-inorganic perovskite solar cells $\cdot$ Power conversion efficiency $\cdot$ Stability $\cdot$ Additives $\cdot$ Passivation

\section{Introduction}

In an era of photovoltaic technology, silicon is an efficient light absorber with relatively high-power conversion efficiency and best stability [1]. But high processing cost to obtain pure silicon has been remained as a challenge since its usage for photovoltaic purpose. To solve such problems, a lot of works have been done. The first application of low-cost semiconductors for photovoltaic was made using cadmium

Getachew Adam Workneh

getachew.adam@aastu.edu.et

1 Department of Industrial Chemistry, Sustainable Energy Center of Excellence, College of Applied Science, Addis Ababa Science and Technology University (AASTU), P.O. Box 16417, Addis Ababa, Ethiopia

2 Division of Soft Matter Physics (SoMaP) and LIT Soft Materials Lab, Johannes Kepler University Linz, Altenberger str. 69, 4040 Linz, Austria

3 Department of Chemistry, College of Natural and Computational Science, Addis Ababa University, P.O. Box 1176, Addis Ababa, Ethiopia selenide (CdSe), cadmium telluride (CdTe), copper indium gallium disulfide $\left(\mathrm{CIGS}_{2}\right)$, amorphous silicon, etc. [2-5]. Even if their processing cost is low, they are not able to compete with crystalline silicon in efficiency and stability. Additionally, they are criticized for toxic components and less abundance [6]. The second attempt was the development of the dye-sensitized, organic molecules and organic semiconducting polymers solar cells [7, 8]. Although they are valued by their interesting properties like flexibility, light weight, colorful appearance and low cost, they lack to fulfill the main requirements for commercial application due to their low power conversion efficiency and stability [9]. The highest record which is reported for the dye-sensitized solar cells is $14 \%$ after a long-time effort with less appreciated stability. After the dawning of semiconducting polymer [10] application of non-fullerene acceptors, the record PCE for organic solar cells is increased to $18 \%$ with undefined stability [11]. Nowadays, low-cost organic-inorganic lead halide perovskite materials which have been represented by general formula, $\mathrm{ABX}_{3},\left(\mathrm{~A}=\mathrm{CH}_{3} \mathrm{NH}_{3}{ }^{+}, \mathrm{CH}\left(\mathrm{NH}_{2}\right)_{2}{ }^{+}, \mathrm{Cs}^{+}, \mathrm{B}=\mathrm{Pb}^{2+}\right.$, $\left.\mathrm{X}=\mathrm{Cl}^{-}, \mathrm{Br}^{-}, \mathrm{I}^{-}\right)$are attracting the photovoltaic community due to its excellent optoelectronic properties such as high 
absorption coefficient [12], tunable band gaps [13], long charge carrier diffusion length [14], low exciton binding energy [15], ambipolar property and flexibility $[16,17]$.

The unprecedented growth in PCE of organic-inorganic perovskite solar cells (OIPSCs) from 3.9\% in 2009 [12] to $25.5 \%$ in 2020 [18] is another factor that motivates researchers and the industry. The rate of publications in the area is highly increased and over 13,200 publications have been published since 2019 [19, 20]. Even though all evidences have been supporting its unprecedented growth in the history of photovoltaic devices, instability towards chemical and physical stresses are profoundly lagging their scalability and commercialization. Thus, unparalleled growth of PCE and long-term stability has been lasting as an assignment for researchers in the area. Large grain boundaries, pinholes, residuals, and current density-voltage (J-V) hysteresis which are resulted from formation of deep and shallow defects in addition to under-coordinated ions or atoms at the surface and/ or interfaces are well-thought-out for unmatched PCE and stability [21-24]. Octahedral tilting, rotations and deformations of corner sharing $\mathrm{PbI}_{6}{ }^{2-}$ octahedra are also suggested for lowering of the performance of the OIPSCs [25-28]. Besides, the chemical, photochemical and thermal instability, organic-inorganic perovskite (OIP) thin films are sensitive to moisture, $\mathrm{O}_{2}$, heat and UV light [29-34].These strengths that incomplete surface coverage of OIP films attributes the formation of non-uniform and rough surface, which scrutinized as deep-trap-density states centers at the grain boundaries (GBs) across the surface or interface of the OIP layer [35]. Defects formation across the interface of HOIP and hole transport layers is considered as a major cause for instability. For example, high PCE devices reported with Spiro-OMeTAD hole transport layer are facing different challenges from instability in ambient air. Even if the active layer is good, oxidative doped Spiro-OMeTAD layer induces leakage of air and moisture towards photoactive layer [36, 37]. As a result, the overall performance of the OIPSCs is abated because of recombination of charge carriers at the surface and/ or across interfaces. The degradation of HOIP in the presence of moisture has been analyzed and may result in the formation of $\mathrm{PbX}_{2}, \mathrm{HX}$, and $\mathrm{X}$ - where $\mathrm{X}=\mathrm{Cl}, \mathrm{Br}$ and I [38-40]. To support this, T.P. Gujar and co-workers [41] studied the role of $\mathrm{PbI}_{2}$ in $\mathrm{CH}_{3} \mathrm{NH}_{3} \mathrm{PbI}_{3}$ perovskite stability, solar cell parameters and device degradation. XRD patterns show residual $\mathrm{PbI}_{2}$ formation on the surface of $\mathrm{CH}_{3} \mathrm{NH}_{3} \mathrm{PbI}_{3}$ films. The results prove that the $\mathrm{PbI}_{2}$ peak intensity increases as annealing time increases, while $\mathrm{CH}_{3} \mathrm{NH}_{3} \mathrm{PbI}_{3}$ peak intensity decreases. This indicates residual $\mathrm{PbI}_{2}$ formation is favored during annealing which lowers the quality of $\mathrm{CH}_{3} \mathrm{NH}_{3} \mathrm{PbI}_{3}$ film. Accordingly, the non-radiative recombination can occur due to the defected surface. To retard the crystallization of $\mathrm{PbX}_{2}$, researchers are working on the effect of chelation or coordination of $\mathrm{Pb}^{2+}$ with ligands. In this regard, addition of ligands or organic salts into OIP solution has shown to improve the PCE and/ or stability of the devices in the ambient air. This approach is mainly based on retarding the crystallization of $\mathrm{PbX}_{2}$ or increasing the crystallization of OIP. Research results show that uniform and smooth morphology of the OIP thin films are obtained by incorporating some appropriate additives [42-44]. Moreover, large grain size or small grain boundaries have been found to slow down deep-trap states, which cause charge recombination on the surface of OIP thin films. In this regard, formation of ionic or covalent or non-covalent bonds between ions or atoms in OIP and additives or passivators is very important to suppress dissociation of OIP films due to physical and chemical stresses [45].

To improve both the PCE and long stability of OIPSCs, researchers are exhaustively working on several mechanisms to reduce high trap-density states in OIP polycrystalline thin films. Compositional engineering, incorporation of additives, interface and surface passivation of light absorber layer, careful selection of charge transport layers, solvent engineering, and use of proper electrode layers get huge attention to minimize barriers towards commercialization of OIPSCs [46-55]. Structural engineering of 3D or 2D configurations is also investigated to get stable and reproducible OIPSCs [56]. The role of deposition techniques on whole performance is also studied as one of the mechanisms to fabricate stable OIP devices [57].

Recently, high-performance devices with significant stability were reported for large-area cells. Such findings inspire scholars in the area to look for different engineering strategies of additives, and surface passivation's to champion OIPSCs in the future. Incorporation of additives into the precursor solutions, and surface passivation of the film has been repeatedly done to inhibit degradation and form defect-free OIP polycrystalline thin films [58-60]. In this mini-review, we are attempting to introduce the efficacies of additives and surface passivation on light absorber and charge transport layers. Additives are compounds which are added to precursors of photoactive film or charge transporting layers in order to improve surface and/or interface optoelectrical properties [61]. Passivation is the process of deactivating (healing) the effect of under-coordinated ions, residual, defects at the grain boundaries and pin holes at the surface or interfaces.

\section{Photoactive layer additives and passivation}

\section{Photoactive layer additives}

Additives are species which are incorporated into targeted material to improve morphological properties for desirable applications. In the history of the photovoltaics technology, 
additives have been applied to enhance the PCE and stability of dye-sensitized, and organic solar cells [62-69]. Nowadays, this approach is extensively used for surface and/or interface treatment of defects of different layers of OIPSCs [70, 71]. Its application has been driven from acid-base adduct formation principle between $\mathrm{Pb}^{2+}$ ions and lone pair electrons of the nitrogen, oxygen or sulfur atoms of additives. Hydrogen bonding between methyl ammonium or formamidinium and additives is also responsible for the immobility of the ions in the structure of OIP [72].

\section{Solvent additives}

Nowadays, solvent engineering has been widely used in the area of OIP photovoltaic to control the crystallization and grain growth during OIP film formation [73, 74]. On the other hand, the interaction of solvent with precursor solution of OIP plays a crucial role in improving the crystal growth of OIP thin film via retarding crystallization of precursors. The effect of weak and strong interaction of solvents with $\mathrm{Pb}^{2+}$ in controlling crystallinity of the targeted OIP was studied [75]. Under this study, the coordinating ability of the processing solvents with the $\mathrm{Pb}^{2+}$ center of the lead halide precursor is reported using Gutmann's donating number, $\mathrm{D}_{\mathrm{N}}$. As a consequence, the solvents which have high $\mathrm{D}_{\mathrm{N}}$ are reported as best solvents, which are strongly interacting with $\mathrm{Pb}^{2+}$. In other words, strong interactions of $\mathrm{Pb}^{2+}$ with solvent keep at the formation of precursor solution and decelerate the crystal growth rate, which is responsible for formation of large-grained crystals of OIP film by decreasing immediate crystallization of lead halides. This indicates that the strength of acid-base interactions between solvent and precursor is very important in the selection of solvents to increase solubility of precursors. Based on this, interactions of two organic solvent molecules, acetonitrile $(\mathrm{ACN})$ and $\mathrm{N}$-methyl-2-pyrrolidone (NMP) with $\mathrm{PbBr}_{2}$ to produce $\mathrm{CsPbBr}$ films are demonstrated by $\mathrm{Y}$. Wu and coworkers [76]. The ACN is reported as the solvent which has weak interactions and NMP as the solvent which has strong interactions with $\mathrm{Pb}^{2+}$. This proves that strong coordination of NMP has resulted in the formation of a uniform and smooth surface of $\mathrm{CsPbBr}_{3}$ film. Consequently, greater PCE and stability are reported for NMP under high relative humidity. Solvent engineering to tune the adduct phase of mixed-cation perovskite precursor film was investigated by M. Wang and co-workers [77]. The XRD patterns (Fig. 1) before and after annealing demonstrate the appearance and disappearance of the adduct phase of mixed-cation precursor film, respectively. It also validates that the quality of precursor film is improved when the volume of DMSO is increased due to the disappearance of unwanted $\delta$-perovskite.

Their work verified that exceeding DMF:DMSO volume ratio beyond 3:5 is decreasing the quality of film due to excess DMSO interaction with $\mathrm{PbI}_{2}$ which results in residual $\mathrm{PbI}_{2}$ after removal of DMSO. These findings are also supported by SEM images of their work (Fig. 2). They suggested that the formation of defect-free and large grainsize crystals of mixed-cation perovskite films from Lewis
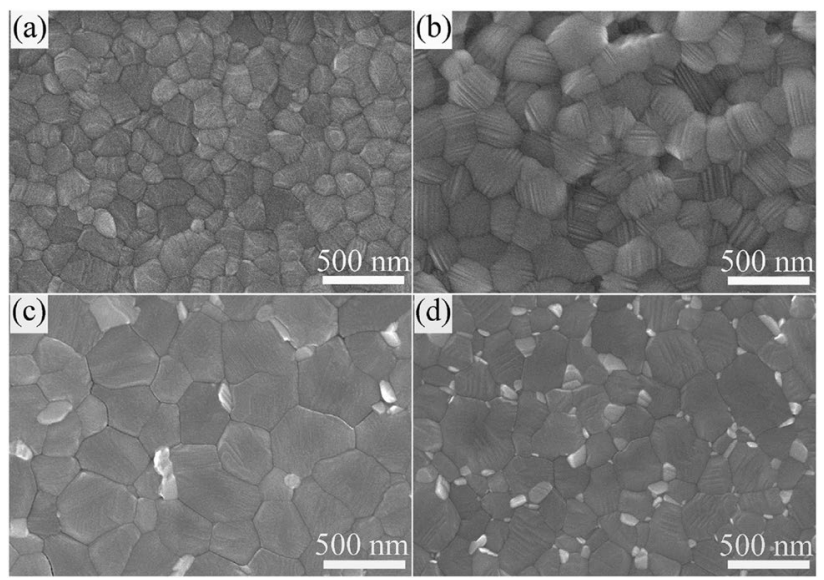

Fig. 2 SEM images of perovskite films based on different DMF/ DMSO volume ratios: a 3:1, b 3:3, c 3:5, d 3:7. Reproduced with permission from [77], Copyright 2019 published by Elsevier Ltd
Fig. 1 XRD patterns of perovskite films with different DMF/ DMSO volume ratios a before and $\mathbf{b}$ after annealing. Reproduced with permission from [77], Copyright 2019 published by Elsevier Ltd
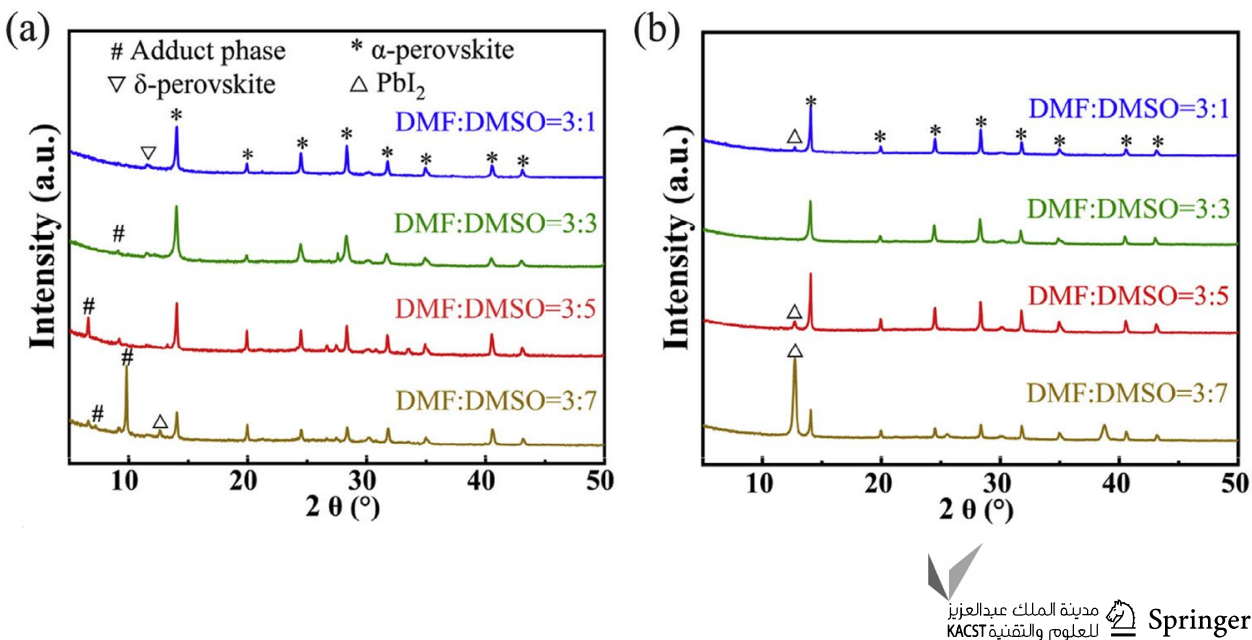
acid-base adduct by solvent engineering attributes for enhanced PCE and stability.

Currently, OIPSCs technology calls for the fabrication of ambient air-stable devices with optimum PCE to compete with silicon solar cells using additives. It is well known that OIPSCs with the highest PCEs are fabricated in the glove box to minimize the effect of moisture and $\mathrm{O}_{2}$. Even though they have shown promising performance in the indoor environment, their performance declines due to degradation of photoactive or transport layers in the outdoor environment. Recently, researchers in the area are scrutinizing the achievement of improved PCE and stable OIPSCs in ambient air for commercialization [29, 52, 78, 79]. Different techniques have been attempted to fabricate efficient and stable OIPSCs in ambient air conditions. In very recent years, introduction of additives into precursor solution of photoactive layers of OIPSCs is widely applied and helps to improve the device performance in the ambient air. G. Wang et al. [80] used N-methyl pyrrolidone (NMP) as an active layer solvent additive to inhibit the formation of non-perovskite polymorph $\left(\delta-\mathrm{FAPbI}_{3}\right)$ in open air. This is because NMP is strongly interacted with $\mathrm{Pb}^{2+}$ to provide ameliorative nucleation for FAI.Pb $\mathrm{Pb}_{2}$.NMP intermediate phase. The co-formation of non-perovskite polymorph $\left(\delta-\mathrm{FAPbI}_{3}\right)$ in the presence of dimethyl sulfoxide (DMSO) is occurred in ambient air. But good solubility of $\mathrm{PbI}_{2}$ in NMP offers a defect-free surface for $\left(\alpha-\mathrm{FAPbI}_{3}\right)$ in ambient air. Better PCE and stability from NMP suggests that there is a probability of scalable fabrication in open air. Bekele et al. used the tendency of acetylacetone solvent additive to solvate $\mathrm{Pb}^{2+}$ and form coordination via two keto-oxygen ligands and demonstrated its dual role to improve the device performance and stability. It has shown to be a promising approach to fabricate a large-area and stable devices with high reproducibility in the ambient environment [81].

Halogenated solvent additives get attention in improving PCE and stability of OIPSCs. P.W. Liang and co-workers [82] reported that the increased coverage and smoothness of the bidentate halogenated solvent additive, 1,8-diiodooctane (DIO) assisted film might be due to improved solubility of $\mathrm{PbCl}_{2}$ in mixed solvent DIO/DMF. They justified the incorporation of DIO with DMF induces fast nucleation and slow rate crystal growth during the film formation. As a result, the whole performance of the device is drastically enhanced.

\section{Organic additives}

The formation of pinholes, small grain sizes, and non-perovskite phases in OIP film bottlenecks the stability and scalability of OIPSCs to date. Researchers in the area are intensively working on different mechanisms and strategies that enhances the performance of OIPSCs. Li et al. [83] applied acetic acid as the additive in an anti-solvent chlorobenzene, to reduce the formation of residual $\mathrm{PbI}_{2}$ on the surface of OIP films. This is supported by results which are obtained from XPS data, shift of peaks for $\mathrm{Pb} 4 \mathrm{f}, \mathrm{C}=\mathrm{O}, \mathrm{O} 1 \mathrm{~s}$. This indicates the presence of interaction between the carbonyl group and $\mathrm{Pb}^{2+}$ ions. Accordingly, the results justify the interaction of $\mathrm{Pb}^{2+}$ with $\mathrm{Pb}^{2+}$ sensitive functional groups has better potential to produce defect-free surfaces which facilitate the charge carrier mobility with long diffusion length. This effect not only improves the surface quality but also it advances the interface quality.

Currently, this strategy is commonly deployed to form large grains which are expedient for charge carrier mobility on the surface of a light absorbing layer. For instance, C. Cui and his co-workers [84] mentioned that the device performance is slow down due to small grains which are associated with abundant grain boundaries. They used the volatile Lewis base, thioacetamide (TAA) as an additive to fabricate uniform films, smooth and high crystalline methylammonium lead iodide films with large grains. Scanning electron microscopy (SEM) images that prove the formation of large grains $\mathrm{CH}_{3} \mathrm{NH}_{3} \mathrm{PbI}_{3}$ films with $1.0 \%$ TAA are shown in Fig. 3. The large grains film formation is verified by the FTIR spectra, which verifies the strong interactions of $\mathrm{Pb}^{2+}$ with TAA and DMSO. Stoichiometric optimization with $1.0 \%$ TAA results in less trap state density and shows a superior PCE of $18.9 \%$. They have also tested that the device with $1.0 \%$ TAA retains $88.9 \%$ of its initial performance after aging for $816 \mathrm{~h}$ in ambient conditions with $25-35 \%$ relative humidity (RH).

\section{Ionic additives}

Charge carriers need smooth and uniform surfaces to offer good electrical conductivity. The contribution of organic salts such as ammonium acetate $\left(\mathrm{NH}_{4} \mathrm{Ac}\right)$ and zinc acetate $\left(\mathrm{ZnAc}_{2}\right)$ in smoothing the surface of hole conductor-free carbon electrode-based perovskite solar cell is worked out by Zhang et al. [85]. Volatile $\mathrm{NH}_{4} \mathrm{Ac}$ gives better smooth surface than non-volatile $\mathrm{ZnAc}_{2}$, which forms pin holes and $\mathrm{PbI}_{2}$ residual on the surface of perovskite films (Fig. 4a). In addition, as shown in the schematic (Fig. $4 \mathrm{~b}, \mathrm{c}$ ) $\mathrm{Zn}^{2+}$ undergoes doping to replace $\mathrm{Pb}^{2+}$, resulting in losing original properties of $\mathrm{MAPbI}_{3}$. XRD patterns also support the findings of SEM images and the crystal structure of $\mathrm{MAPbI}_{3}$ in the presence of the salts. This suggests that using suitable salts may mitigate defect induced recombination in low-cost carbon-based perovskite films. Accordingly, ammonium salts such as $\mathrm{NH}_{4} \mathrm{Cl}$ and $\mathrm{NH}_{4} \mathrm{SCN}$ additives in SpiroOMeTAD hole conductor for $\mathrm{CH}_{3} \mathrm{NH}_{3} \mathrm{PbI}_{3-\mathrm{x}}(\mathrm{SCN})_{\mathrm{x}}$-based planar PSCs yields better results in ambient air [86].

Cationic compositional engineering in perovskite solar cells has shown a blooming effect in improving both PCE and stability [87-89]. Studies related to cationic 


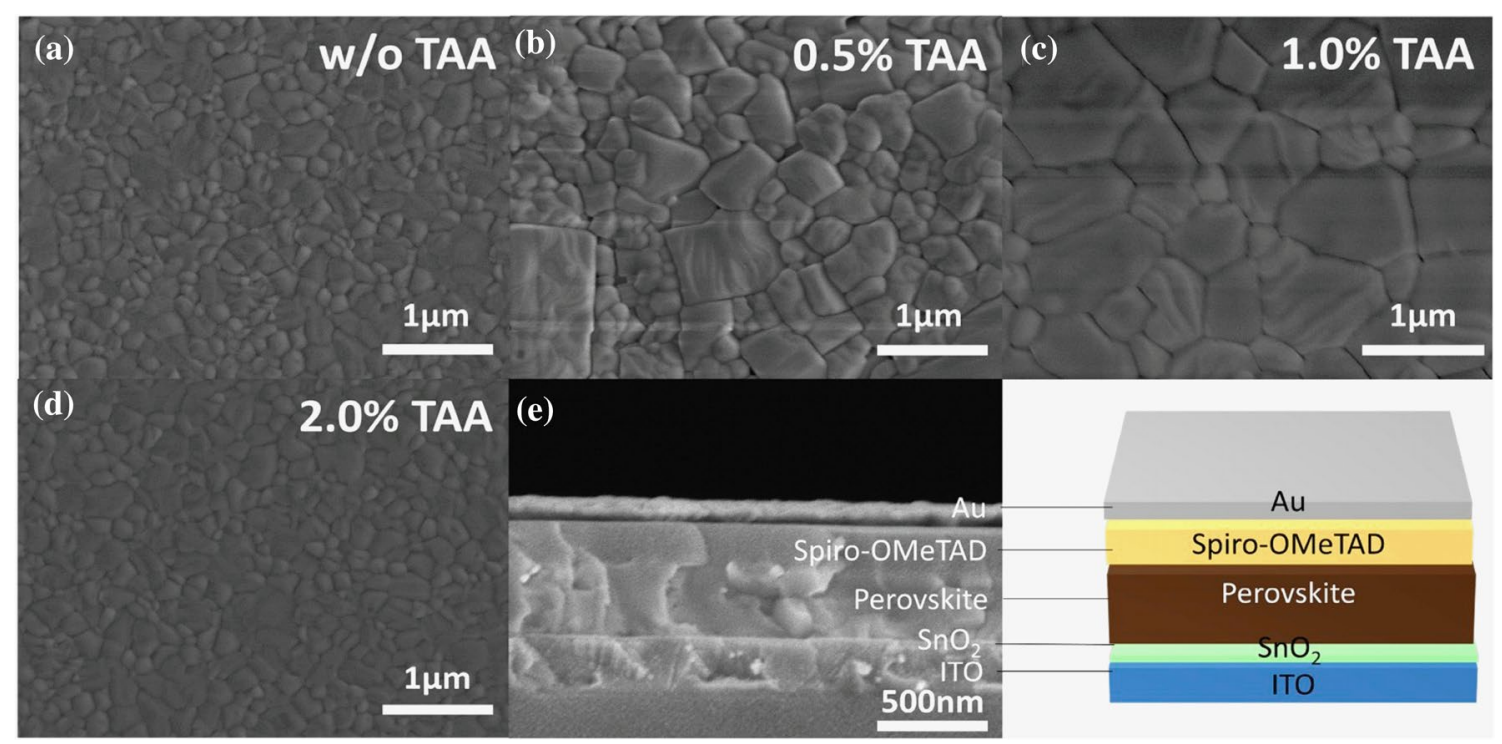

Fig. 3 a-d Top view SEM images of perovskite films with various TAA contents $(0,0.5,1.0$ and $2.0 \%)$. e Cross-sectional SEM image and the schematic structure of the perovskite solar cell device with
1.0\% TAA. Reproduced with permission from [84], Copyright 2020 Published by Elsevier B.V
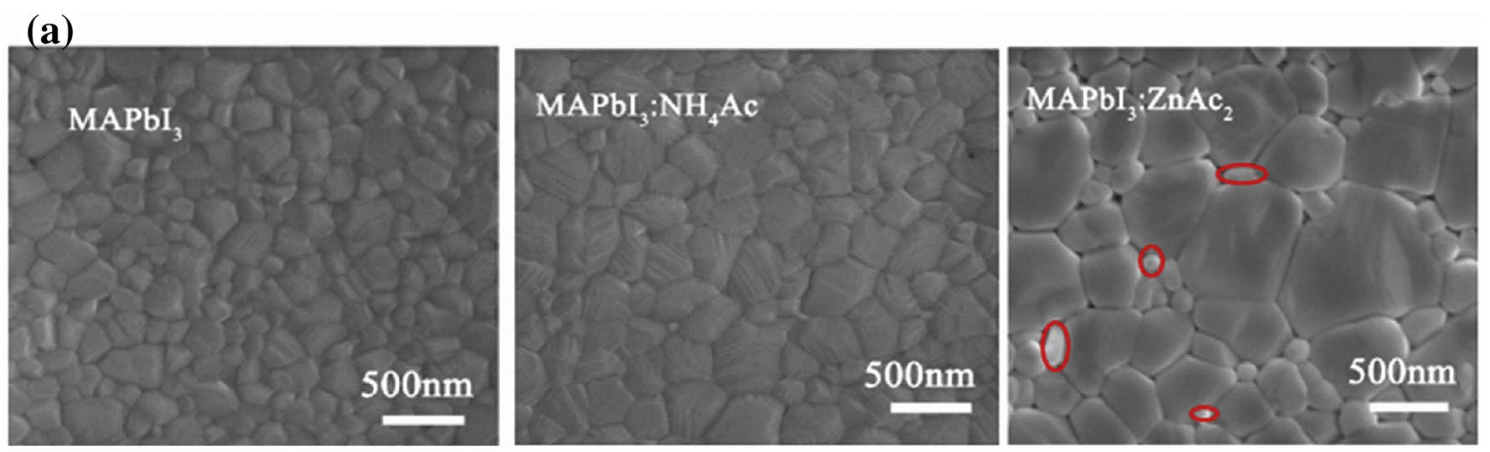

(b)
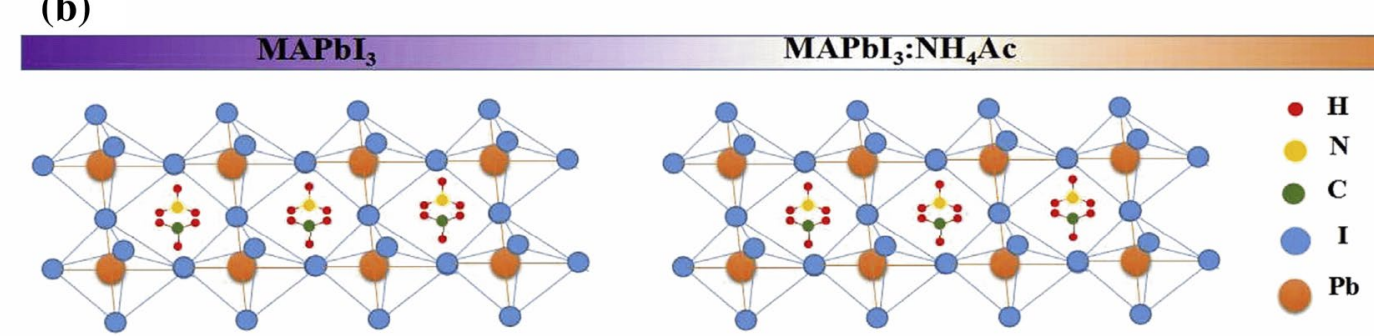

(c)
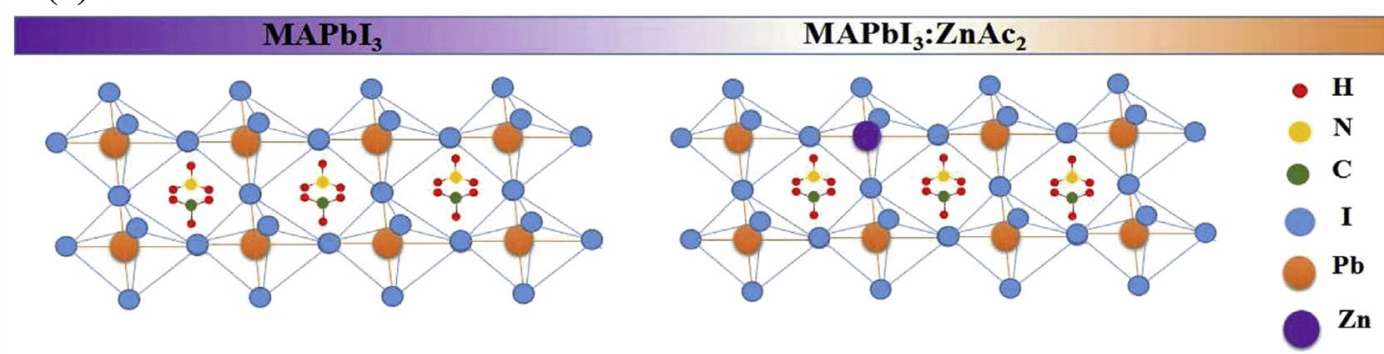

Fig. 4 a Top view SEM images of the three types of films deposited on $\mathrm{FTO} / \mathrm{TiO}_{2}$ substrates by one-step method (without carbon layer). The circular marks correspond to $\mathrm{PbI}_{2} . \mathbf{b}$, $\mathbf{c}$ Schematic diagram of the crystal structure of $\mathrm{MAPbI}_{3}$ and $\mathrm{MAPbI}_{3}: \mathrm{NH}_{4} \mathrm{Ac}, \mathrm{MAPbI}_{3}$ and $\mathrm{MAPbI}_{3}: \mathrm{ZnAc}_{2}$. Reproduced with permission from [85], Copyright 2019 Published by Elsevier B.V 
engineering shows that the interchange or mixing of cations induces change in optical properties, whereas partial or full substitution of $\mathrm{Pb}$ ions or halide ions results in tuning of the electrical properties of the OIPs. M. Kim et al. [90] investigated that the incorporation of methylammonium chloride (MACl) builds an intermediate phase which is transformed into the high quality pure $\alpha$-phase $\mathrm{FAPbI}_{3}$ film. Disappearing of $\delta-\mathrm{FAPbI}_{3}$ and $\mathrm{PbI}_{2}$ during annealing of the film in the presence of $\mathrm{MACl}$, and the formation of high quality pure $\alpha$-phase $\mathrm{FAPbI}_{3}$ film is justified by experimental results as shown in Fig. 5. X-ray diffraction (XRD) spectra (Fig. 5A), reciprocal full width at half maximum (FWHM) (Fig. 5B), time-resolved photoluminescence (TRPL) (Fig. 5E) and steady state photoluminescence spectra (Fig. 5F) measurements for pristine, $10 \%, 20 \%, 30 \%, 40 \%$ and $50 \%$ of MACl were reported by the group. But films with $40 \% \mathrm{MACl}$ at $150{ }^{\circ} \mathrm{C}$ show large grains size. The corresponding device yield of PCE is exceeding $24 \%$ with significant thermal stability from pure $\alpha$-phase $\mathrm{FAPbI}_{3}$.

The role of surfactant-based additives in improving the PCE and stability of perovskite solar cells gives the room to use and look for them [91, 92]. J. Hong et al. [93] used poly(ethylene glycol) tridecyl ether (PTE) as a non-volatile polymer additive. Introducing ultra-small amount (less than $0.1 \mathrm{wt} \%$ ) of PTE into the perovskite precursor solution controls the kinetics of crystallization. This facilitates the charge carrier mobility at the surface and interface of inverted OIPSCs.

\section{Passivation of photoactive layer}

Nowadays, passivation approach becomes the most popular strategy to minimize the recombination centers in either photoactive layer or interfaces between light absorber and charge transport layers [22, 94-96]. Different molecules have been developed to avoid and stabilize different types of defects, which are triggering non-radiative recombination at the surface and/ or interfaces of the perovskite layer in different structures of OIPSCs [43, 97]. Passivation of the surface or interface can occur by either chemical or physical processes. Chemical passivating agents undergo reaction with charged or neutral species at the surface and/ or interface before the generation of charge carriers. Physical passivating agents treat grain boundary defects and pin holes via physical interaction and improve surface coverage. To support this, M.S. Lee and co-workers [98] used a simple bidentate organic molecule, pyrazine (Pyr), which is undergoing both chemical and physical passivation. Pyr forms bidentate coordination with $\mathrm{Pb}^{2+}$ to prevent electrons reaction. This indicates that chemical passivation inhibits the reduction or oxidation of ions at the surface or interface of photoactive layer to produce neutral atoms or molecules. They reported that insertion of Pyr boosts the PCE of the device. One of the problems on the surface during operation is the chemical reaction which changes the optoelectronic properties of OIP film. Using co-passivating additives reduces the chemical reactions which are taking place on the surface. Guo and co-workers [99] applied 1H, 1H-Perfluorooctylamine (PFA) as a co-passivating agent. The comparative results
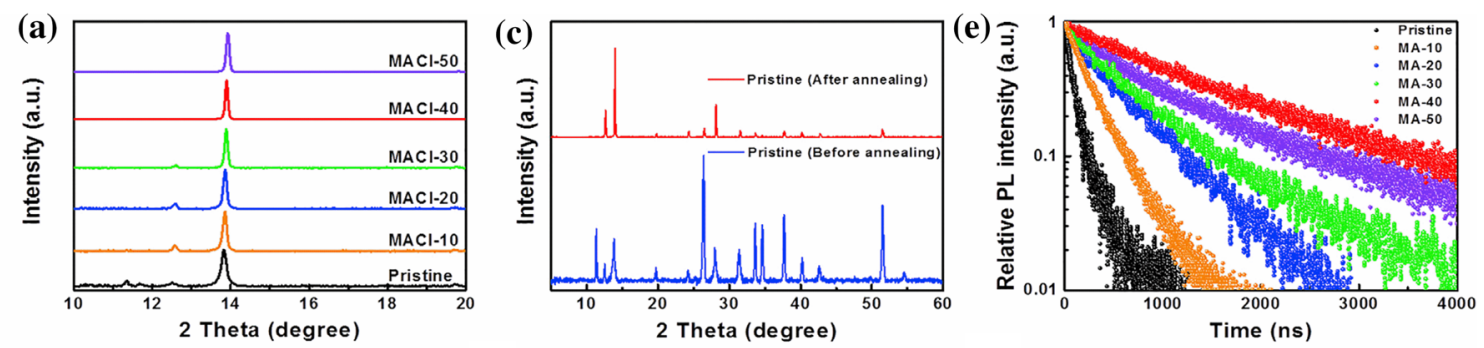

(b)

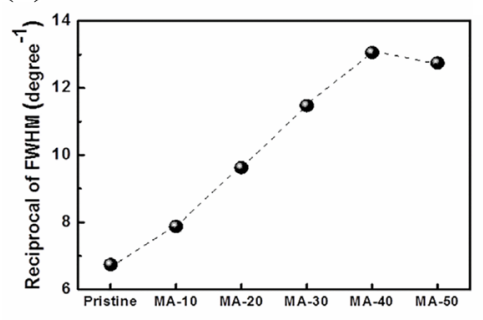

(d)

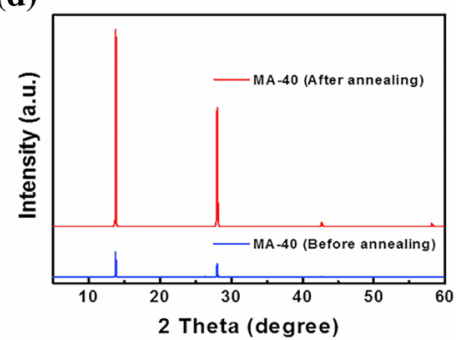

(f)

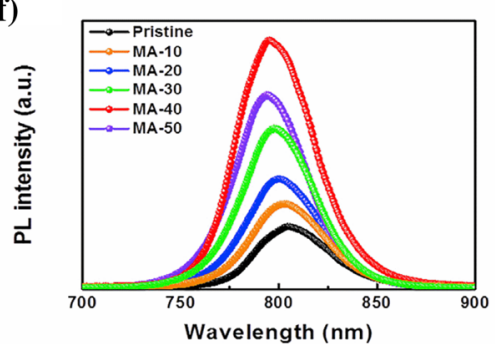

Fig. 5 A, B, E, F XRD spectra, reciprocal FWHM at the diffraction peak 13.9 and photoluminescence data of perovskite films, respectively. C XRD data obtained from perovskite films prepared without $\mathrm{MACl}$ before and after annealing at $150{ }^{\circ} \mathrm{C}$ for $10 \mathrm{~min}$. D XRD data obtained from perovskite films prepared with MA-40 before and after annealing at $150{ }^{\circ} \mathrm{C}$ for $10 \mathrm{~min}$. Reproduced with permission from [90], Copyright 2019 published by Elsevier Inc 
between films with and without PEA show the importance of co-passivating agents for better performance of OIPSCs. Consequently, it helped to achieve promising results which motivate to design and synthesis other efficient co-passivating agents to fabricate large-area OIPSCs. PEA via chlorobenzene (antisolvent) was introduced as co-passivating agent which simultaneously lowers the surface and grain boundary defects.

The existence of defects or impurities in semiconductors has potential to change the optical and electrical properties of the semiconductors in both negative and positive aspects [100-102]. For example, impurities in silicon increase electrical conductivity. But in OIPSCs, the presence of bulk defects and impurities reduces the electrical conductivity due to non-radiative recombination of charge carries [103-105]. Accordingly, they beget current-voltage $(I-V)$ hysteresis, reduced PCE and instability for the device. D. Aidarkhanov et al. [106] showed that the defects at the interface of $\mathrm{SnO}_{2} /$ mixed perovskite layers is passivated by introduction of optimal amount of organic cross linker, 2,2'-(ethylenedioxy)bis(ethylammonium iodide) (EDAI) at the interface. The study shows that problems which are created because of defects can be solved by using suitable additives at the interface. $I-V$ hysteresis that may be rooted due to ion migration [107], or charge trap states [108] across interfaces is significantly reduced and the PCE of the device is increased with better stability. Dissolution of OIPs in a humid environment, which has some ionic and covalent characteristics [109], may cause loss of optoelectronic properties. This attributes to the formation of hydrated phases and lead halides on the surface of OIPs films [110,111]. Based on this, different hydrophobic additives have been developed to mitigate the impact of moisture. C.F. AriasRamos et al. [112] applied a mixture of ethyl acetate (EA) and 4-tertbutyl-pyridine (tBP) as hydrophobic anti-solvent additive to extract the primary solvent from the precursor solution. The results suggested that using appropriate hydrophobic anti-solvent with proper optimization may give room to fabricate highly stable OIPSCs outside glovebox atmosphere. Liu et al. [113] demonstrated that polymethyl methacrylate (PMMA) passivate the interface of cesium formamidinium methyl ammonium lead triiodide ( $\left.\mathrm{CsFAMAPbI}{ }_{3}\right)$ / Spiro-OMeTAD and methyl ammonium lead triiodide $\left(\mathrm{MAPbI}_{3}\right) /$ Spiro-OMeTAD in planar perovskite solar cells. Though doped Spiro-OMeTAD is appreciated for achievement of the highest PCE, it is reproached for oxidation at high temperature and infiltration of water through it to the photoactive layer. The insertion of hydrophobic PMMA between light absorbing and hole transport layer boosts both PCE and stability in outdoor because it reduces percolation of water. It is also acknowledged for having higher $\mathrm{V}_{\mathrm{OC}}$ and FF and less hysteresis compared to corresponding reference devices. Incorporation of polymethyl methacrylate (PMMA) into the PTAA hole transport layer is also reported and it provides high hydrophobic nature for the layer [114]. On the other hand, it improves the crystallinity of the OIP films by preventing moisture. Carbonyl groups of the PMAA contribute large grain formation. This helps to yield better PCE and stability for inverted structure.

Li et al. [115] reported that addition of quinolone to $\mathrm{CH}_{3} \mathrm{NH}_{3} \mathrm{PbI}_{3}$ precursor solution effectively suppresses the non-radiative recombination of carriers by co-passivating the defects at surface and grain boundaries. The XRD patterns prove the interaction between $\mathrm{Pb}^{2+}$ and lone pair electrons in quinolone, which confirms the formation of Lewis acid-base adduct. The optimized device with less hysteresis, improved stability and high PCE indicates that quinolone and compounds from the quinolone family can be applied as effective OIP additives. The high cost and less stable states of some hole transport materials forces to manufacture hole-free OIPSCs. Adding most favorable polyethylene glycol (PEG) concentration into $\mathrm{MAPbI}_{3}$ precursor solution produced high surface coverage and large grain size [116]. However, it behaves hygroscopic; it prevents OIP film from moisture and delivers interesting stability for the device. This is because it is preventing water molecules from reaching the surface of OIP films. Y.H. Lin et al. [117] reported the effect of additives on the thermal stability of mixed OIPSCs. It has been shown that the incorporation of organic-inorganic ionic salt additive 1-butyl-1-methylpiperidinium tetrafluoroborate $\left([\mathrm{BMP}]^{+}\left[\mathrm{BF}_{4}\right]^{-}\right)$into the perovskite absorber minified deep-trap states. They justified that defects in $\mathrm{Cs}_{0 .}{ }_{17} \mathrm{FA}_{0.83} \mathrm{~Pb}\left(\mathrm{I}_{0.77} \mathrm{Br}_{0.23}\right)$ based perovskite solar cells have been passivated through reaction between $\left([\mathrm{BMP}]^{+}\left[\mathrm{BF}_{4}\right]^{-}\right)$and photogenerated superoxide and peroxide species from the surface of $\mathrm{Cs} 0_{{ }_{17}} \mathrm{FA}_{0.83} \mathrm{~Pb}$ $\left(\mathrm{I}_{0.77} \mathrm{Br}_{0.23}\right)$ film [57]. This effect improves the performance and enhances the operational thermal stability of mixed OIPSCs which is stressed under full-spectrum sunlight at elevated temperatures up to $85^{\circ} \mathrm{C}$. In another study the impacts of lead halide residual are removed by adding an optimum amount of tetrabutyl ammonium bromide (TBAB) salt into pristine OIP films [118]. The role of TBAB is measured in terms of crystal growth kinetics alteration $[119,120]$. As a result, it improved the PCE, stability and negative impact of the hysteresis.

Mixed dimensional structure is another approach to improve stability of OIPSCs [56, 121-124]. Studies show that, however, two-dimensional (2D) OIPs are more stable than three-dimensional (3D), their low PCE is not yet attractive [125]. To surpass the whole performance of the 2D OIPSCs, introduction of organic additives resulting in good quality of OIP crystal structure [126]. Zheng et al. [127], studied the synergistic effect of additives on 2D OIP films. N,N-dimethyl sulfoxide (DMSO) and thio-semicarbazide (TSC) were introduced as additives into the precursor

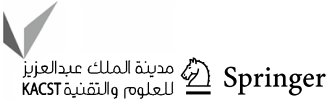


solution. Consequently, trap state density of 2D OIP film is reduced and evidently about $93 \%$ increment of PCE and improved stability were achieved after the addition of additives. These results clearly magnify the positive impacts of additives on the whole performance of 2D OIPSCs. Other studies affirm that formation of the mixed 3D/2D structure yields efficient and stable perovskite solar cells in the presence of additives [128, 129]. D. Yao et al. demonstrated the capability of long-chain alkylamine organic compounds in hindering moisture permeation towards light absorbing layer [130]. As discussed in preceding part, the work proves that post-device treatment with vapor of diethyltriamine (DETA) and triethylenetetraamine (TETA), transformed 3D OIPs to lower dimensional (LD) crystals on account of partial substitution of cation by either DETA or TETA. Accordingly, the LD perovskite crystals are passivating 3D layers from moisture and deep-trap states across the interface.

Current studies are focusing on zwitterion molecules, which can bind with negatively and positively charged defects. These defects are intrinsic in nature, and they are supposed to be vacancies and ions at the surface and/ or interfaces. Thus, zwitterion type molecular passivators help to solve such problems by binding to two sites simultaneously. The comparative study between pyridine treated and pyridinium iodide, zwitterion molecule, was conducted by Y. Du and co-workers to indicate the role of zwitterion molecule in boosting the whole performance of the mixedcation perovskite solar cells [131]. To suppress cationic and anionic defects from the surface and interface of OIP, low-cost ammonium chloride was used [132]. It passivates negatively charged cation vacancy defects by $\mathrm{NH}_{4}{ }^{+}$and positively charged vacancy defects by $\mathrm{Cl}^{-}$. As a result, imperfection of polycrystalline OIP film was improved and PCE of $21.38 \%$ was achieved.

Inverted architecture in perovskite solar cells has been widely used to solve the stability problems which are incorporated with mesoporous and planar devices [133, 134]. Emerging inverted perovskite solar cells which have used moisture sensitive and highly acidic poly (3, 4-ethylenedioxythiophene) polystyrene sulfonate) PEDOT:PSS as a hole transport layer are not stable enough and are less efficient [135]. J-V hysteresis are common problems in PEDOT:PSS integrated PSCs. To resolve this effect, inorganic hole transport materials are applied in inverted PSCs [136, 137]. Even if stability of inverted PSCs is upgraded due to incorporation of inorganic hole transport materials, their efficiency is not sufficient for scalability of OIPSCs. In recent times, different groups show interest to resolve the negative impacts of PEDOT:PSS by adding efficient additives at ITO/PEDOT:PSS or PEDOT:PSS/ perovskite interface or light absorber or charge transport layer surfaces [138-140]. Zhou and co-workers [141] studied on synergetic effects of multiple functional ionic liquid,
EMIC (1-Ethyl-3-methylimidazolium chloride) treated PEDOT:PSS and S-acetylthiocholinechloride passivated perovskite surface. The result show improvement in PCE as well as stability of ITO/PEDOT:PSS(EMIC)/ $/ \mathrm{CH}_{3} \mathrm{NH}_{3} \mathrm{PbI}_{3} / \mathrm{S}$ acetylthiocholinechloride/C60/BCP/Ag configuration for a large area. An increase in electrical conductivities for the mentioned device is explained by an increase in the amount of PEDOT in the bipolaron states because of doping and the formation of defect-free OIP surface. Attempt to augment the performance of inverted PSCs has motivated the group of Zheng [142] to explore the role of n-butylamine (BA), phenethylamine (PEA), octylamine (OA) and oleylamine $(\mathrm{OAm})$ in modifying grain boundaries and interface of the light absorber. They have found that long-chain alkylamine ligands (AALs) have potential to subdue deep-trap densities at the surface and/ or interfaces. This method enables them to achieve an inverted champion device with a PCE of $23 \%$ with significantly improved operational stability. It is well known that under-coordinated ions in OIPs are responsible for $\mathrm{I}-\mathrm{V}$ hysteresis in the presence of mobile ions in the crystal. To prevent this issue, researchers are dedicated in looking for efficient passivation of ions migration. Luo et al. [138] demonstrated the effectiveness of ionic liquid, 1-methyl-3-propylimidazolium bromide (MPIB), in passivating under-coordinated $\mathrm{Pb}^{2+}$ in the perovskite film. The formation of $\mathrm{PbI}_{2}$ residual during OIP film annealing in pristine and disappearance of under-coordinated $\mathrm{Pb}^{2+}$ in the presence of MPIB was proved using X-ray diffraction (XRD) (Fig. 6). This affects the quality of crystal growth for OIP film with enhanced thermal stability. Hence, improved PCE with negligible $I-V$ hysteresis was reported from passivation of under-coordinated $\mathrm{Pb}^{2+}$ using MPIB. On other hands, ionic or hydrogen bond interactions could be favored when additives are purposefully added to precursors of OIP or OIP solution. Group of Choi [143] worked on the role

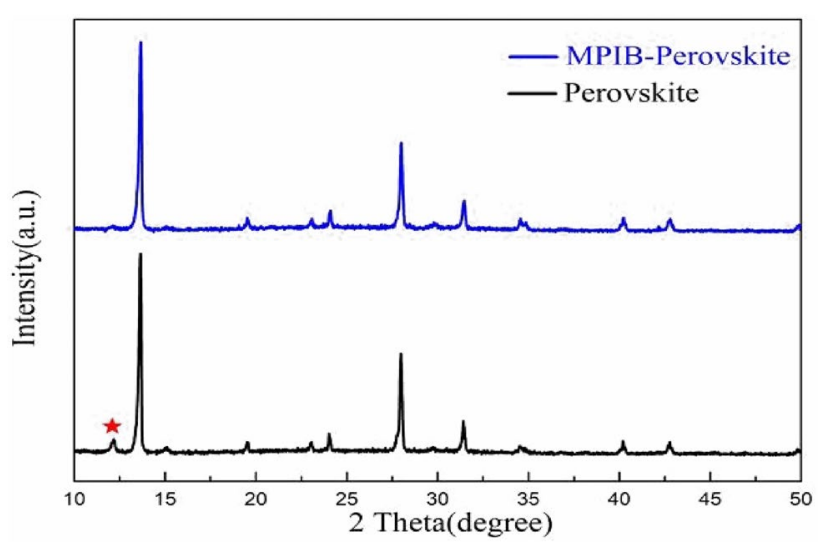

Fig. 6 X-ray diffraction (XRD) of the pristine perovskite and MPIBperovskite (0.5) films. Reproduced with permission from [138], Copyright 2020 Royal Society of Chemistry 
Scheme 1 Schematic representation of the interaction between perovskite and TMA. Reproduced with permission from [144], Copyright 2019 Published by Elsevier B.V

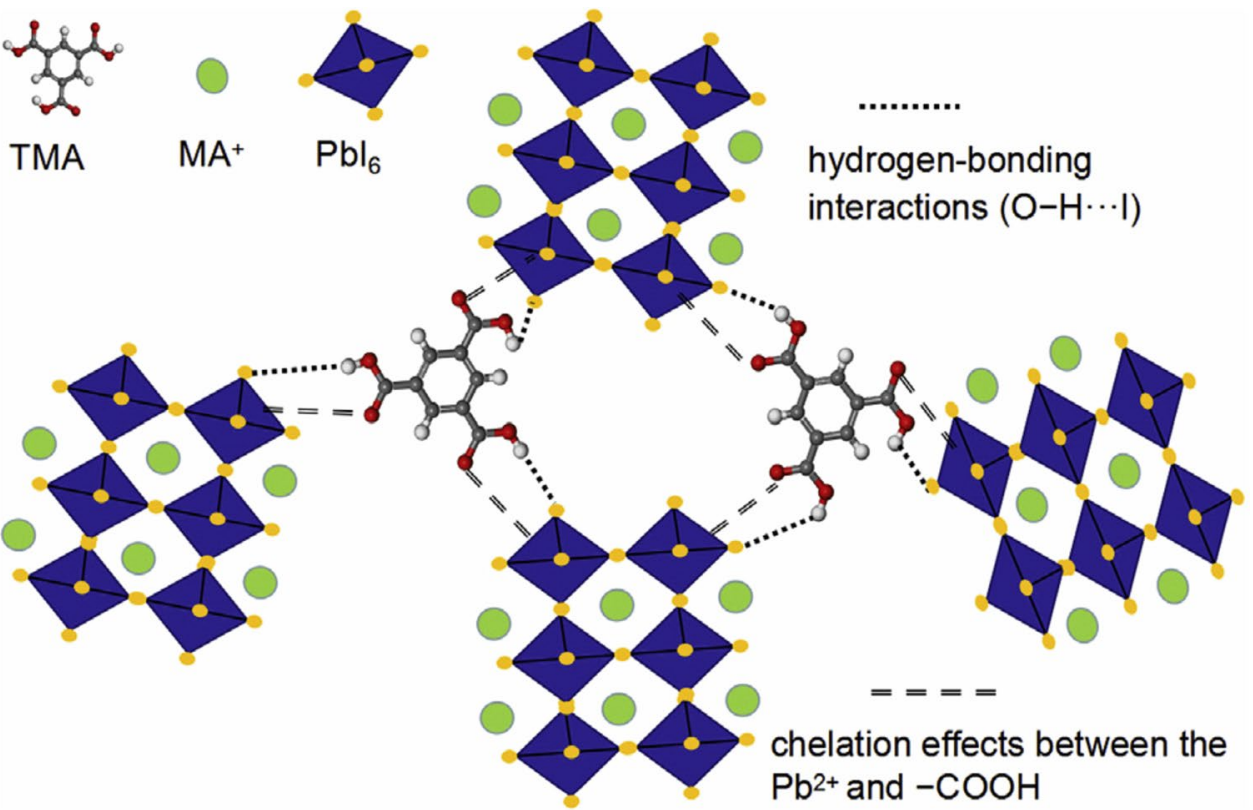

of functional additives in performance of inverted planar OIPSCs. They found that $\mathrm{OH}$ functional groups in 2-hydroxyethyl acrylate (HEA) is strongly interacted with organic cation $\left(\mathrm{CH}_{3} \mathrm{NH}_{3}{ }^{+}\right.$or $\mathrm{HC}\left(\mathrm{NH}_{2}\right)_{2}{ }^{+}$. They proved that the crystallinity and grain sizes of OIP are improved and rate of non-radiative recombination is decreased. As a result, they achieved the highest PCE of $20.40 \%$ for a large-area (1.08 $\mathrm{cm}^{2}$ ) inverted planar OIPSCs. Under this study, the longterm stability is also reported for OIP with HEA.

Morphology improvement in crystalline semiconducting materials is very crucial to increase electrical conductivity. Kinetics of crystallization justifies that slow crystallization process attributes for large grains size of crystal. This effect is modifying the surface and interface optoelectronic properties of the materials. During OIP film formation, unreacted lead halides or cation halides in a solution contribute for incomplete surface coverage of the film. In 2019, Su et al. [144] engaged in the fabrication of defect-free OIP film using a two-step solution method in the presence of trimesic acid (TMA) as an additive in the lead precursor solution. It is reported that coordination of oxygen atoms in TMA with $\mathrm{Pb}^{2+}$ in lead precursor solution to form an intermediate which slows down fast crystallization to control the course of crystallization. Furthermore, the existence of hydrogen bonding between hydroxyl group of TMA and iodide in perovskite is depicted (Scheme 1) under this study. The cumulative effect of hydrogen bonding interactions with perovskite and oxygen atoms interactions with $\mathrm{Pb}^{2+}$ in the precursor solution is able to produce stable and pinholes-free large grain-sized perovskite film.

Mechanical instability is the major challenge to fabricate flexible solar cells which is also common issue in flexible perovskite solar cells. It is believed that the addition of polymer additives can resolve such problems [140]. Based on this, Yao and co-workers reported the effectiveness of polymer additives in improving the morphological quality and mechanical instability of flexible perovskite solar cells [145]. By doing this, they obtained mechanically stable device. This shows that the addition of the optimum amount of polymer alloy additives has great potential to fabricate wearable electronics which are flexible. Similarly, S. Ma et al. [146] introduced N,N'-bis-(1-naphthalenyl)-N,N'-bisphenyl-(1,1'-biphenyl)-4,4'-diamine (NPB), to fabricate uniform and pin holes-free OIP films. In addition to that, they mentioned that NPB offers good communication between PEDOT:PSS and OIP film due to its ability to adjust the energy level mismatch between PEDOT:PSS and OIP layers. The valence band energy of $\mathrm{MAPbI}_{3}$ and the HOMO energy level of PEDOT:PSS are $-5.43 \mathrm{eV}$ and $-4.92 \mathrm{eV}$, respectively. But the HOMO energy level of NPB is -5.40 , which is able to adjust the mismatch between the two layers. This bestows enhanced performance for inverted flexible $\mathrm{MAPbI}_{3}$ solar cells under a humid atmosphere and UV light.

Additives which have ion migration blocking effect in perovskite solar cells are highly effective in eliminating I-V hysteresis. In addition to this, such additives contribute to reduce recombination centers by providing large grainsized crystallinity for OIP films. In this regard, K. Zhu et al. [147] investigated the role of ethylamine alcohol chloride (EA.HCl) which contains hydroxyl (-OH) and ammonium cation $\left(-\mathrm{NH}_{3}{ }^{+}\right)$as the additive to reduce ion migration in the perovskite film. They verified that halide ion interactions in perovskite through hydrogen bonds of $-\mathrm{OH}$ or coordination of $-\mathrm{NH}_{3}{ }^{+}$passivate defects and avoid ion migrations.

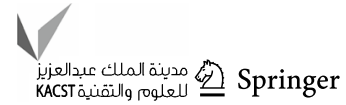




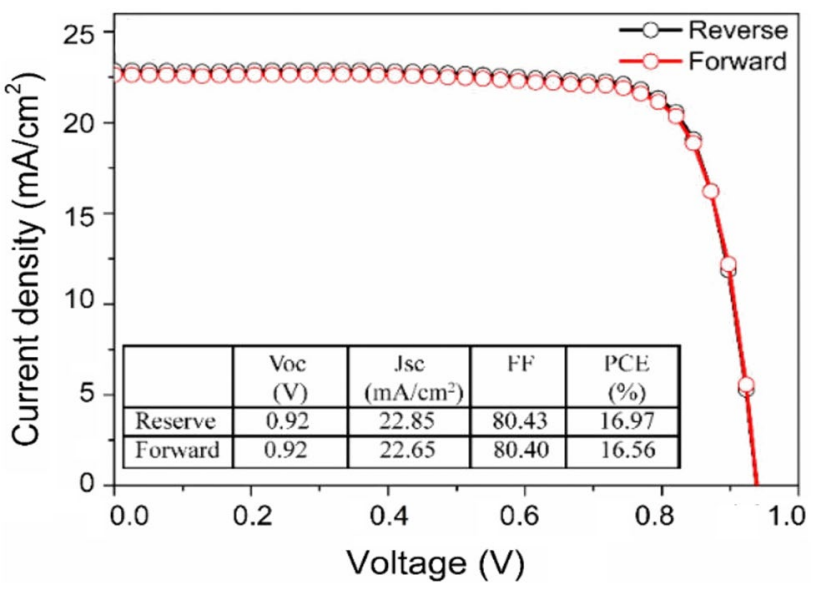

Fig. 7 Current density-voltage (J-V) curves of devices with 1 wt\% $\mathrm{EA} \cdot \mathrm{HCl}$ additive for reverse and forward scans. Reproduced with permission from [147], Copyright 2019 Published by Elsevier B.V

The introduction of the optimal amount of EA.HCl enables to fabricate devices with improved PCE and negligible $I-V$ hysteresis (Fig. 7).

Researchers use different organic compound additives containing carbonyl group to investigate its role to improve the PCE and stability of perovskite devices. Lately, Wang et al. [148] studied that strong interaction of $\mathrm{C}=\mathrm{O}$ groups in caffeine with $\mathrm{Pb}^{2+}$ increases the activation energy of nucleation, which delays crystal growth to improve crystallinity of the OIP films. The finding suggests that caffeine and related alkaloids can improve the electrical conductivity and operational stability in ambient air. Inspiring results from biomaterial, betulin, which contains hydroxyl $(-\mathrm{OH})$ functional groups and give a chance to use biologically active materials to passivate under-coordinated ions defects at the surface or interfaces of OIP [149]. Thus, the experimental and theoretical results show that the hydrogen bonds of betulin lock methylamine and halogen ion along the grain boundaries. This work reports the highest PCE, 21.15\%, with remarkable chemical and thermal stability.

The effect of electrostatic force to avoid the surface and interface drawbacks is inspected. Zhang et al. [150] observed that the addition of chenodeoxycholic acid (CDCA) stabilizes the $\mathrm{FAPbI}_{3}$ film by electrostatic interaction between FAI and CDCA in which CDCA passivated the surface and interfaces of $\mathrm{FAPbI}_{3}$. Moreover, the effect of passivation is justified by shift of HOMO and LUMO energy levels after treatment which forms better communication at the interface of pristine and CDCA treated OPI films (Fig. 8). Other study by Xin et al. [151] also assures that the electrostatic interactions of molecules with positively and negatively charged point defects are declining the number of charge trapping centers from the surface by adding 2-amino-5-cyanopyridine (ACP), which contains electron-withdrawing (cyano) and

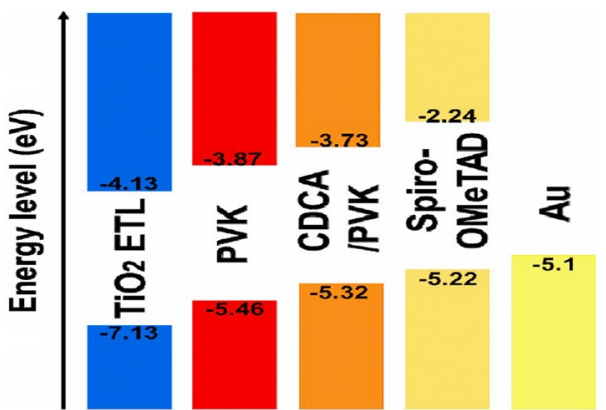

Fig. 8 Energy levels and band structure diagram of functional layers for PVSC. Reproduced with permission from [150], Copyright 2020 Published by Elsevier B.V

electron donating (amine) groups into OIP film. The study suggested that similar features of ACP molecule with the zwitterion to bind with negatively and positively charged point defects of the film decreases the charge recombination rate across the surface or interface of the film. The result indicates that incorporation of ACP imparts good mechanical stability besides improving the PCE for regular flexible OIPSCs.

Even though mesoporous configurations of OIPSCs are noted in their highest PCE at this time, they are known for their fast degradation [152]. To maintain the PCE of mesoporous structure and improve the stability of devices, Xie et al. [153] applied three amides viz; formamide (FAM), acetoamide (AAM) and propionamide (PAM) to passivate the surface and regulate crystallographic structures. The result shows that $5 \%$ of AAM yields over $20 \%$ of PCE with better stability for meso-configured OIPSCs. They rationalized that strong interaction between $\mathrm{AAM}-5 \%$ and $\mathrm{Pb}^{2+}$ is responsible for formation of smooth and uniform crystalline film for the enhancement of the performance. The formation of residual of $\mathrm{PbI}_{2}$ is one of the common problems as a surface defect of perovskite films. Nishihara et al. [154] used formamidinium bromide (FABr) to react excess $\mathrm{PbI}_{2}$ to form $\mathrm{FAPbBr}_{3-x} \mathrm{I}_{x}$. The strategy is effective in passivating the surface of the film and facilitates the charge transport process.

Challenges in the case of the PCE and long-term stability of OIPSCs are mainly dealt with defects across of the HTL/light absorber layers interface. But defects at the interface of ETL/OIP layers have been causing immense problems, which are altering the optoelectronic properties of the interface. Amphoteric imidazole as passivator in inverted OIPSCs structure was tested [155]. It improves the quality of crystals as well as it reduces defects at the surface and grain boundaries. Consequently, imidazole treated OIP yields devices with promising PCE and stability. The derivative of imidazole, 2-methylbenzimidazole was introduced at the interface of $\mathrm{SnO}_{2} / \mathrm{OIP}$ film to solve defects-related anomalies [156]. Binding of the under-coordinated $\mathrm{Pb}^{2+}$ 
with lone pairs of 2-methylbenzimidazole to form acid-base adduct decreases the number of charge trapping centers. This approach yields devices with PCE of $21.6 \%$ having better humidity and thermal stability. Similarly, imidazolium iodide is used as auto-passivator to produce $\mathrm{MAPbI}_{3}$ and imidazole iodide [157]

Li et al. [158] studied organophosphorous ligands (trioctylphosphine oxide (TOPO) and triphenylphosphine oxide (TPPO)) as passivators. The results affirm that TPPO is more effective than TOPO. This is because benzene rings are facilitating charge transfer across the interface of HTM and photoactive layer in addition to oxygen atom which is an electron-rich center to bind with under-coordinated $\mathrm{Pb}^{2+}$. Dual advantages of TPPO result in the improved PCE and stability of the device. The group of Wu reported the potential of applying other organophosphorous compounds like tributyl phosphine (TBUP), triphenyl phosphine $\left(\mathrm{PPh}_{3}\right)$, and trioctylphosphine (TOP) in reducing and oxidizing iodine $\left(\mathrm{I}^{\mathrm{O}}\right)$ and lead $\left(\mathrm{Pb}^{\circ}\right)$ atoms defects [159]. TBUP is found to be more effective in reducing volatile $\mathrm{I}^{\mathrm{O}}$ and an oxidized form of TBUP is oxidizing $\mathrm{Pb}^{0}$ to $\mathrm{Pb}^{2+}$. The studies show that the catalytic TBUP, which is passivating the defects, is integrated with tributyl phosphine oxide, which is binding with under-coordinated $\mathrm{Pb}^{2+}$, to subdue recombination impacts. So, it offers long-term operational thermal stability with attractive PCE for doped Spiro-OMeTAD containing perovskite solar cell.

Triphenyl(9-ethyl-9H-carbazol- 3-yl)-phosphonium bromide (TCPBr) and iodide (TCPI) were also applied as passivator of the OIP film [160]. The films which are without and with TCPBr and TCPI treatment are characterized by $\mathrm{XRD}$. Results indicate that the amount of $\mathrm{PbI}_{2}$ is increasing after one month for pristine because of moisture but it is very low after two months in case of treated OIP films. This ascertains the great capability of TCPBr and TCPI in improving PCE and stability of Spiro-OMeTAD HTL-based perovskite solar cell.

N, N'-bis-(1, 1, 1, 2, 2, 3, 3, 4, 4-nonafluorodo- decan6-yl)-perylenediimide (F-PDI), which is conductive, and hydrophobic organic molecule is analyzed for its competency in improving PCE and stability [161]. Its carbonyl groups which bind with under-coordinated $\mathrm{Pb}^{2+}$ passivate the surface. Besides that fluoro groups which are interacted with methyl ammonium cation to form hydrogen bonding provide immobility for monovalent cation. This strategy is crucial to ward off the phase transition of the cubic structure of OIP during annealing [162, 163].

Wu et al. [164] have revealed the potential of three kinds of large alkylammonium iodides viz. phenylethylammonium iodide, (PEAI), 1,4- butanediammonium iodide (BDAI), and guanidinium iodide (GAI) as passivating interlayer between hole transport layer and OIP layer in inverted structure. Their integration as an interlayer suppressed non-radiative recombination processes, which indicate their passivating role. Moreover, they enhanced charge selectivity from OIP to HTL. BDAI interlayer increased the open circuit voltage (Voc) of the device without affecting short-circuit current density (Jsc) and fill factor (FF). These features helped to yield a competitor PCE for inverted OIPSCs with negligible hysteresis.

\section{Charge transporting layers additives and passivators}

It is well known that the total number of charge carriers which are transported via charge transporting layers is critical to harvest maximum PCE. But different defects in charge transporting layers are acting as trapping centers of charge carriers and lowering the performance of the OIPSCs. For example, mesoporous $\mathrm{TiO}_{2}$ as an electron and doped SpiroOMeTAD as hole transport layers are widely deployed in OIPSCs technologies [165]. Devices with mesoporous $\mathrm{TiO}_{2}$ are showing better PCE than devices based on dense $\mathrm{TiO}_{2}$ which is due to an increase in surface area of the light absorber [166]. But both mesoporous scaffolds of $\mathrm{TiO}_{2}$ and dense $\mathrm{TiO}_{2}$ suffers from a large number of oxygen vacancies, which are deliberated as trapping centers for electrons. The commonly used additives are infused to charge transporting layers to form uniform and smooth surface morphology. Not only that, they helped to have good communication between the interface of charge transporting and other layers in OIPSCs by reducing charge carriers trapping centers, but they can also adjust energy level alignments [167, 168]. Lose in the original properties of charge transporting layers in the presence of moisture, $\mathrm{O}_{2}$, and UV-Vis light has been lowering PCE and stability of perovskite solar cells. For this reason, different surface or interface properties modifiers have been emerged to manage such problems.

\section{Solvent-based additives}

Organic halides or lead halide crystalline aggregates formation on the surface during OIP film fabrication investigated as a contributor for charge carriers recombination. Recent works point out that some charge transport materials which are suspicious towards the formation of aggregates [46, 169, 170]. Solvent additive engineering is used to minimize the causes which are responsible for formation of aggregates due to charge transporting layers. Ye et al. [171] worked on engineering of a series of solvent additives (1,8-diiodoctane, 1-chloronaphthalene, 1-phenylnaphtha-lene, 1-methylnaphthalene) to improve the influence of electron transport layer, perylene diimide derivatives (PDIs) in the film morphology and transport process. They found that 1-methylnaphthalene (MN) was the best solvent additive to control the effect of

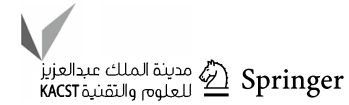


aggregates in 1,1'-bis(2-methoxyethoxyl)-7,7'-(2,5-thienyl) bis-(BIS-PDI-EG) films. In general, addition of 1-methylnaphthalene into perylenediimide derivatives (PDIs) was effective in improving both PCE and stability of the OIPSCs.

\section{Organic compounds-based additives}

Hygroscopic dopant, lithium bis(trifluoromethanesulfonyl) imide (Li-TFSI), in Spiro-OMeTAD-based perovskite solar cells is responsible for fast decay of the device performance as a result of aggregate formation. Searching for hydrophobic dopants which will substitute Li-TFSI is very crucial to increase the electrical conductivity of Spiro-OMeTAD layer in ambient air condition. Hydrophobic alkaline-earth bis(trifluoromethanesulfonyl)imide additives such as $\mathrm{Mg}$ TFSI $_{2}$ and Ca-TFSI ${ }_{2}$ were developed by N.D. Pham and co-workers to increase moisture resistivity of the SpiroOMeTAD [172]. Comparative study of Li-TFSI, Mg-TFSI ${ }_{2}$ and Ca-TFSI ${ }_{2}$ by using different methods reveals that alkaline-earth bis(trifluoromethanesulfonyl)imide additives have better potential than Li-TFSI. For instance, the calculated hole mobilities for $\mathrm{Mg}-\mathrm{TFSI}_{2}$ and $\mathrm{Ca}-\mathrm{TFSI}_{2}$ are greater than Li-TFSI. Consequently, they obtained noteworthy PCE and stability from Spiro-OMeTAD-based OIPSC.

The main purpose of dopants in Spiro-OMeTAD is to oxidize the HTL. Consequently, thionyl chloride $\left(\mathrm{SOCl}_{2}\right)$ dopant which is capable of generating more oxidized states of spiro-OMetAD was developed by the group of $\mathrm{Li}$ [173]. The experimental findings prove that the optimum amount of $\mathrm{SOCl}_{2}$ increases the concentration of holes as well as its mobility to achieve better PCE. The instability which is criticized in the presence Li-TFSI is upgraded by inclusion of $\mathrm{SOCl}_{2}$ because of suppression of density of defect states from the interface. Moreover, Hu et al. [174] studied the effectiveness of fullerene and its derivatives as OIP additives to improve the PCE and stability of OIPSCs in ambient conditions. They observed that addition of these materials to OIP solution improves the crystal quality, enlarges grain size and reduces grain boundaries. Consequently, the electron extraction and transport have been increased in OIP films. The FTIR spectra prove that the formation of Lewis acid-base adduct from $\mathrm{Pb}^{2+}$ and $\mathrm{C}_{60}$ derivatives and weakening of dissolution of $\mathrm{PbI}_{2}$ in the presence of moisture. As a result, they reported improved stability from nitrogen containing C60 derivatives in ambient environment. The development of naphthalene imide dimer (2FBT2NDI) by group of H. Wang [175] resulted in achieving maximum PCE of inverted OIPSCs. They affirmed the effectiveness of it in passivating the surface and interface of OIP layer. The same forward and reverse current scans indicate, defects and ions which are causing hysteresis are negligible in the device. Furthermore, it facilitates electron extraction across the interface of OIP/PCBM. So, the summative qualities of 2FBT2NDI integration offer the maximum PCE for inverted OIPSC. Poly $\left(2,2^{\prime}\right.$-bithiazolothienyl-4, $4^{\prime}, 10,10^{\prime}$ tetracarboxydiimide) (PDTzTI) which contains sulfur, nitrogen and oxygen functional groups was also used as ETL in inverted OIPSCs [176]. In addition to charge selectivity, it is passivating the interface of OIP due to possible interactions between $\mathrm{Pb}^{2+}$ and the functional groups (Fig. 9). The synergistic effect of this polymer yields greater PCE (20.86\%) than 2FBT2NDI, which is the highest for inverted structure to date. Hydrophobic nature of PDTzTI is also benefiting to improve the long-term operational stability of OIPSCs.

Similarly, 4',4"'-(1,3,4-oxadiazole-2,5-diyl)bis $(N, N$ bis(4-methoxyphenyl)-[1,1'-biphenyl]-4-amine) was designed and synthesized as HTL to transport holes and passivate the $\mathrm{Pb}^{2+}$ by Lee et al. [177]. They found that methoxy functional groups in the HTL are very important in adjusting energy alignment of HOMO of HTL with OIP.

Alkoxy-PTEG HTM with multifunctional groups was designed and synthesized by Lee et al. [178]. The presence
Fig. 9 Schematic illustration of the perovskite/PDTzTI interfaces. The enlarged area describes the possible interactions between unsaturated $\mathrm{Pb}$ ions (likely $\mathrm{Pb}$ trap/defect sites) and functional group (N, S, O) presented in the PDTzTI ETLs. Reproduced with permission from [176], Copyright 2019 Published by Elsevier Ltd
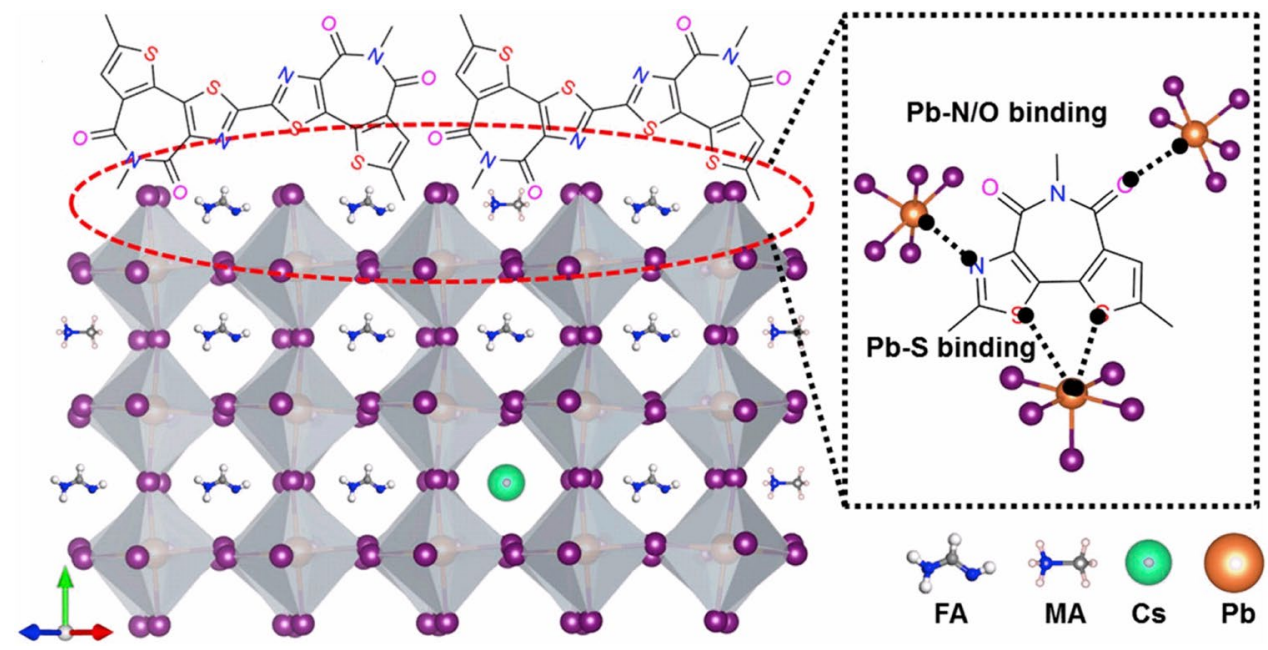
of alkoxy groups in it offers multipurpose advantages. For example; (1) it increases solubility of alkoxy-PTEG in nonaromatic green solvent (3-methyl cyclohexanone) which is occurring naturally, (2) it prevents the leakage of lead ions by chelating with it, (3) it enhances the electrical conductivity of alkoxy-PTEG, which is comparable with doped SpiroOMeTAD and (4) it exhibits improved Voc and FF. AlkoxyPTEG HTM which is processed in nonaromatic green solvent exhibits inviting PCE (19.9\%) from $\mathrm{SnO}_{2}$ planar OIPSCs. On the other hand, dopant-free alkoxy-PTEG HTM which is processed in 2-methyl anisole (2-MA) which is an aromatic solvent with low toxicity potential shows $21.2 \%$ of PCE which is reported as the highest value. Besides these, it improves chemical and thermal stability of OIP films.

\section{lonic-based additives}

Oxygen vacancies in commonly used $\mathrm{ETL}, \mathrm{TiO}_{2}$ are considered as trapping centers for electrons, which are causing non-radiative recombinations in regular OIPSCs [179-181]. Unstability due to $\mathrm{TiO}_{2}$ demands several approaches which can reduce side effects in regular planar perovskite solar cells. NaCl-assisted defect passivation study has been done to empower electrons extraction of $\mathrm{TiO}_{2}$ by $\mathrm{Li}$ et al. [182]. They reported that $\mathrm{Na}^{+}$ions-doped $\mathrm{TiO}_{2}$ improved the wettability of OIP films. As a result, $5 \% \mathrm{Na}$-doped $\mathrm{TiO}_{2}$ shows the remarkable change in average grain size and grain boundaries of the perovskite layer (Fig. 10).

In addition, oxygen vacancies in $\mathrm{TiO}_{2}$ which are scavenging electrons are deactivated by incorporation of $\mathrm{NaCl}$ salt. Thus, electron transporting potential of $\mathrm{TiO}_{2}$ is enhanced. Also the measured higher recombination resistance owing to $\mathrm{NaCl}$ has contributed significant change in long-term stability and hysteresis in n-i-p perovskite solar cells. Also, Sun et al. [183] asserted the role of optimum $\mathrm{Na}_{2} \mathrm{~S}$ to passivate $\mathrm{TiO}_{2}$ and OIP surfaces. Herein, $\mathrm{Na}^{+}$ions are doping the $\mathrm{TiO}_{2}$, while $\mathrm{S}^{2-}$ ions are interacting with $\mathrm{Pb}^{2+}$ ions to form covalent bonds, which are ruled out by soft acid-base principle. $\mathrm{Na}^{+}$ions-doped $\mathrm{TiO}_{2}$ increased wettability degree of OIP films as mentioned by Li et al. [182]. As a result, experimental results verify that incorporation of $\mathrm{Na}_{2} \mathrm{~S}$ passivated the interface and improved the crystallinity of OIP films. Significant change has been observed in current density and Voc of planar OIPSCs fabricated after incorporation of $\mathrm{Na}_{2} \mathrm{~S}$ into $\mathrm{TiO}_{2}$ ETLs. The other study (Fig. 11) on inverted perovskite solar cells using surfactant additives has been reported by Wang et al. [184].

They coated an ultrathin sodium dodecyl benzene sulfonate (SDBS) on the surface of nickel oxide $\left(\mathrm{NiO}_{x}\right) \mathrm{HTL}$, that is between HTL and light absorber layer. They explained that the reason for good communication at the interface of $\mathrm{NiO}_{\mathrm{x}} /$ perovskite surface is surface wettability potential of SDBS. Thus, the SDBS is adjusting the surface wettability

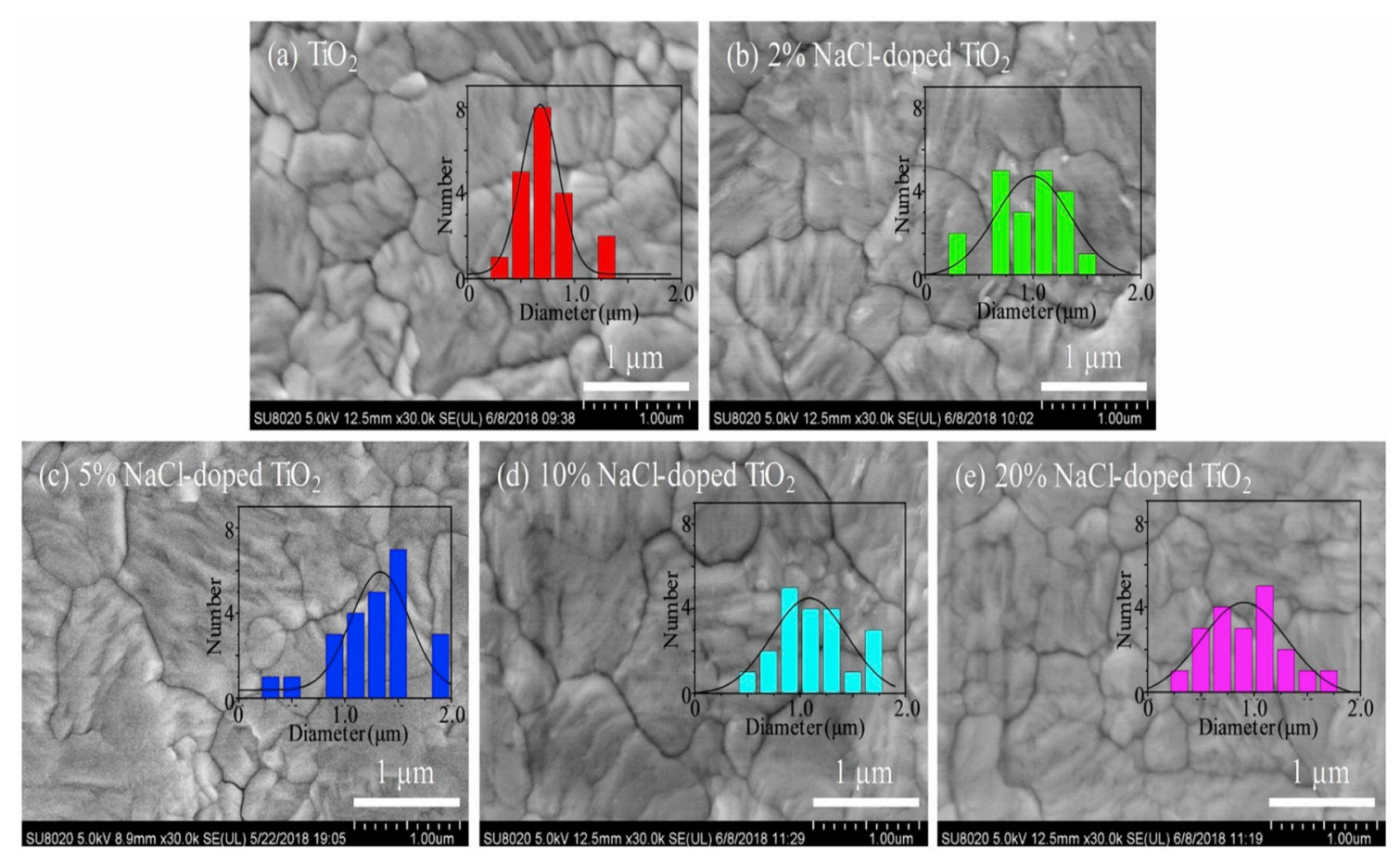

Fig. 10 SEM images of the perovskite layer fabricated on a the pristine and b $2 \%$, c 5\%, d $10 \%$, and e $20 \%$ Na-doped $\mathrm{TiO}_{2}$ films, respectively. The insets are the statistic distributions of grain size analyzed from individual images. Reproduced with permission from [182], Copyright 2019 Published by Elsevier B.V 


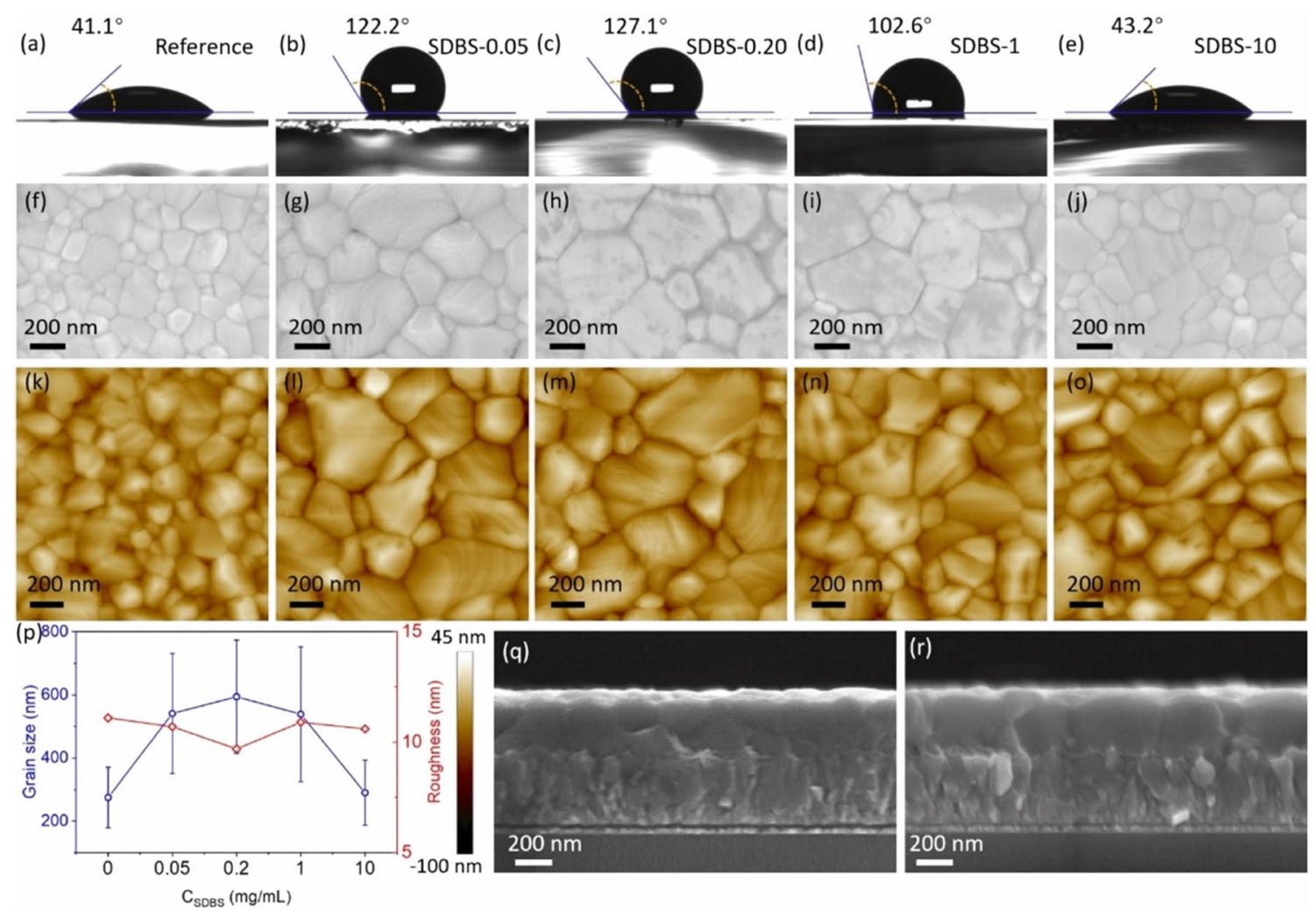

Fig. 11 The contact angle of water on the NiOx/SDBS film with different concentrations $\left(\mathrm{mg} \mathrm{mL}^{-1}\right)$ of SDBS: a 0 , b 0.05 , c 0.20 , d 1 and $\mathbf{e} 10$. Top view SEM and AFM images of perovskite films deposited on NiOx/SDBS film with different concentrations $\left(\mathrm{mg} \mathrm{mL}^{-1}\right)$ of SDBS: $0(\mathbf{f}, \mathbf{k}), 0.05(\mathbf{g}, \mathbf{l}), 0.20(\mathbf{h}, \mathbf{m}), 1(\mathbf{i}, \mathbf{n})$ and $10(\mathbf{j}, \mathbf{o})$. p Statis-

of $\mathrm{NiO}_{\mathrm{x}}$ to form a fully covered perovskite film, which provides high quality crystalline perovskite film.

In general, the role of some additives and passivators in improving PCE, Jsc, Voc, and FF of the different perovskite solar cells since 2019 is summarized in Table 1. Their role in improving the chemical, mechanical and thermal stability of the device is also noticed as the foremost merit.

\section{Conclusions and outlooks}

Even though the power conversion efficiency of OIPSCs has been promising to go over the Shockley limitation of silicon solar cells, still their instability has been remained as a gap. Managing the factors which are causing degradation of layers, charge recombination across the interface and surface and hysteresis of OIPSCs is very crucial. Different approaches like compositional engineering, optimizing deposition techniques, solvent engineering, anti-solvent engineering, and additives/passivators engineering have been applied to abate the common problems in these devices. tics of grain size and surface roughness of perovskite films deposited on $\mathrm{NiOx} / \mathrm{SDBS}$ film with different concentrations of SDBS solution. Cross-sectional SEM images of perovskite layers grown on NiOx film $\mathbf{q}$ without and $\mathbf{r}$ with SDBS layer. Reproduced with permission from [184], Copyright 2019 Published by Elsevier B.V

Nowadays, different additives are fruitful in ameliorating poor crystallinity of the photoactive layer. They have been also applied in adjusting energy alignment between photoactive and charge transporting layers. Even if hydrophobic approaches have been leading to prevent moisture interaction, hydrophilic surface passivation which is paradoxical approach has been becoming efficient in improving moisture instability as well as PCE due to hydrogen bonding.

Degree of intra- or inter-molecular interactions between additives/passivators and photoactive or charge transporting layers or defects is determining the status of OMHPSCs stability. Accordingly, studies show that the binding energy of the atoms or ions can be used to relevant technique to determine stability of the materials or devices. Thus, detailed study on the binding energy of the different additives/passivators atoms or ions with organo-metal halide perovskites or charge transporting layers or surface defects is vital to select worthy additive to obtain homogenized and well-ordered surfaces for ease transportation of charge carriers and stable state of materials. In general, additives/passivators engineering has becoming promising strategy to look for different 
Table 1 Comparative summary of OIPSCs in the presence of additives/passivators and the reference cells

\begin{tabular}{|c|c|c|c|c|c|c|}
\hline Additives/passivators category & Device with & $J_{\mathrm{sc}}\left(\mathrm{mA} / \mathrm{cm}^{2}\right)$ & $\operatorname{Voc}(\mathrm{V})$ & FF & PCE $(\%)$ & References \\
\hline \multirow[t]{12}{*}{ Solvent } & DMF/DMSO & 23.13 & 1.16 & 0.79 & 21.2 & \multirow[t]{2}{*}{ [77] } \\
\hline & Reference & 22.91 & 1.11 & 0.69 & 18.3 & \\
\hline & $\mathrm{DMF}+\mathrm{DMSO} 1.5 \mathrm{eq}$ & 24.21 & 0.95 & 0.61 & 14.11 & \multirow[t]{2}{*}{ [73] } \\
\hline & DMF & 18.13 & 0.85 & 0.56 & 8.65 & \\
\hline & NMP $1.0 \%$ & 7.64 & 1.57 & 0.83 & 9.53 & \multirow[t]{3}{*}{ [76] } \\
\hline & $\mathrm{ACN} 1.0 \%$ & 7.60 & 1.57 & 0.82 & 9.22 & \\
\hline & Reference & 7.05 & 1.56 & 0.81 & 8.27 & \\
\hline & $\mathrm{C} 60 / \mathrm{BCP}$ & 21.33 & 1.08 & 0.73 & 17.02 & \multirow[t]{2}{*}{ [185] } \\
\hline & Reference & 17.97 & 1.07 & 0.71 & 12.31 & \\
\hline & DMSO & 21.32 & 0.96 & 0.68 & 14.01 & \multirow[t]{3}{*}[80]{} \\
\hline & NMP & 23.30 & 1.00 & 0.74 & 17.29 & \\
\hline & Reference & 22.68 & 0.97 & 0.71 & 15.53 & \\
\hline \multirow[t]{29}{*}{ Small organic molecules/polymer } & Formic acid $0.764 \mathrm{M}$ & 23.59 & 1.10 & 0.77 & 19.81 & \multirow[t]{2}{*}{ [186] } \\
\hline & Reference & 23.01 & 1.07 & 0.73 & 17.82 & \\
\hline & Acetyl Acetone (AA) & 18.50 & 0.99 & 0.76 & 14.00 & \multirow[t]{2}{*}{ [81] } \\
\hline & Reference & 17.40 & 0.95 & 0.73 & 12.10 & \\
\hline & Acetic acid $8 \vee \%$ & 24.31 & 1.15 & 0.82 & 23.00 & \multirow[t]{2}{*}[83]{} \\
\hline & Reference & 22.90 & 1.11 & 0.75 & 19.10 & \\
\hline & TAA $1.0 \%$ & 22.91 & 1.11 & 0.74 & 18.91 & \multirow[t]{2}{*}{ [84] } \\
\hline & Reference & 22.70 & 1.09 & 0.69 & 17.01 & \\
\hline & PFA (CsFAMA) & 24.10 & 1.14 & 0.78 & 21.31 & \multirow[t]{2}{*}{ [99] } \\
\hline & Reference & 23.42 & 1.11 & 0.75 & 19.53 & \\
\hline & Quinoline $0.4 \mathrm{M}$ & 23.07 & 1.14 & 0.79 & 20.87 & \multirow[t]{2}{*}{ [115] } \\
\hline & Reference & 22.48 & 1.11 & 0.75 & 18.65 & \\
\hline & TBAB $7.5 \mathrm{mM}$ & 23.41 & 1.12 & 0.77 & 20.16 & \multirow[t]{2}{*}{ [118] } \\
\hline & Reference & 21.49 & 1.10 & 0.75 & 17.56 & \\
\hline & Pyrazine $0.5 \mathrm{mg} / \mathrm{mL}$ & 23.07 & 1.13 & 0.79 & 20.10 & \multirow[t]{2}{*}[98]{} \\
\hline & Reference & 23.06 & 1.09 & 0.77 & 18.79 & \\
\hline & Y-Th2 & 23.7 & 1.14 & 0.80 & 21.50 & \multirow[t]{2}{*}{ [187] } \\
\hline & Reference & 21.9 & 1.09 & 0.77 & 18.3 & \\
\hline & AIA & 22.85 & 1.02 & 0.68 & 15.70 & \multirow[t]{4}{*}[188]{} \\
\hline & HIA & 23.05 & 1.05 & 0.71 & 17.29 & \\
\hline & $\mathrm{CA}$ & 23.49 & 1.10 & 0.74 & 19.06 & \\
\hline & Reference & 21.06 & 0.97 & 0.66 & 13.60 & \\
\hline & Benzoic acid (BA) $3 \%$ & 21.19 & 1.05 & 0.75 & 16.26 & \multirow[t]{2}{*}{ [189] } \\
\hline & Reference & 19.00 & 1.05 & 0.77 & 14.83 & \\
\hline & HEA & 23.74 & 1.11 & 0.80 & 21.01 & \multirow[t]{2}{*}{ [143] } \\
\hline & Reference & 21.95 & 1.07 & 0.77 & 18.17 & \\
\hline & 2,2'-bipyridine (Bpy) $1 \%$ & 23.17 & 1.07 & 0.77 & 19.02 & \multirow[t]{3}{*}{ [190] } \\
\hline & $2,2^{\prime}: 6^{\prime}, 2^{\prime \prime}$-terpyridine (Tpy) $0.2 \%$ & 23.07 & 1.06 & 0.76 & 18.68 & \\
\hline & Reference & 22.48 & 1.05 & 0.74 & 17.58 & \\
\hline
\end{tabular}


Table 1 (continued)

\begin{tabular}{|c|c|c|c|c|c|c|}
\hline Additives/passivators category & Device with & $J_{\mathrm{Sc}}\left(\mathrm{mA} / \mathrm{cm}^{2}\right)$ & $\operatorname{Voc}(\mathrm{V})$ & FF & PCE $(\%)$ & References \\
\hline & $\mathrm{EC}$ & 22.33 & 1.13 & 0.77 & 19.46 & [191] \\
\hline & PC & 22.5 & 1.13 & 0.78 & 19.63 & \\
\hline & PPC & 22.62 & 1.14 & 0.78 & 20.06 & \\
\hline & Reference & 22.18 & 1.10 & 0.74 & 17.88 & \\
\hline & PTE $0.017 \%$ & 19.69 & 1.08 & 0.80 & 16.76 & [93] \\
\hline & Reference & 18.762 & 1.06 & 0.77 & 15.49 & \\
\hline & PS & 21.67 & 1.06 & 0.77 & 18.60 & [192] \\
\hline & PCE10 & 21.69 & 1.08 & 0.80 & 19.60 & \\
\hline & Reference & 21.94 & 1.08 & 0.82 & 18.20 & \\
\hline & PEG $10 \%$ & 21.68 & 0.98 & 0.55 & 11.62 & [116] \\
\hline & Reference & 18.82 & 0.93 & 0.44 & 7.74 & \\
\hline \multirow[t]{20}{*}{ Ionic compounds } & $\mathrm{BMIMBF}_{4} 0.3 \%$ & 23.80 & 1.08 & 0.81 & 19.80 & [193] \\
\hline & Reference & 23.20 & 1.02 & 0.79 & 18.50 & \\
\hline & Zinc acetate & 22.60 & 0.92 & 0.59 & 12.30 & {$[85]$} \\
\hline & Ammonium acetate & 24.35 & 0.98 & 0.59 & 13.88 & \\
\hline & Reference & 21.75 & 0.93 & 0.55 & 11.11 & \\
\hline & {$[\mathrm{BMP}]^{+}\left[\mathrm{BF}_{4}\right]^{-} 0.25 \mathrm{~mol} \%$} & 19.50 & 1.16 & 0.77 & 17.30 & {$[117]$} \\
\hline & Reference & 19.50 & 1.11 & 0.75 & 16.60 & \\
\hline & TBUB-TBPO pair & 22.97 & 1.13 & 0.79 & 20.48 & {$[159]$} \\
\hline & Reference & & & & 19.54 & \\
\hline & $\mathrm{NH}_{4} \mathrm{Cl}$ & 19.66 & 1.03 & 0.72 & 14.71 & {$[86]$} \\
\hline & $\mathrm{NH}_{4} \mathrm{SCN}$ & 21.17 & 1.05 & 0.75 & 16.61 & \\
\hline & Out additive/passivator & 18.52 & 1.03 & 0.68 & 12.97 & \\
\hline & (BMImI) $0.2 \%$ MWCNT & 27.98 & 1.085 & 0.7325 & 21.39 & {$[194]$} \\
\hline & Reference & 23.63 & 0.82 & 0.65 & 12.56 & \\
\hline & $\mathrm{PbTiO}_{3} 0.05 \mathrm{M}$ & 21.72 & 1.00 & 0.49 & 10.55 & {$[195]$} \\
\hline & Reference & 18.98 & 0.91 & 0.43 & 7.46 & \\
\hline & Spiro-OMeTAD: $\mathrm{MoS}_{2} 0.6 \%$ & 24.48 & 1.10 & 0.75 & 21.18 & {$[196]$} \\
\hline & Spiro-OMeTAD & 23.54 & 1.05 & 0.72 & 17.79 & \\
\hline & $\mathrm{MACl} 40 \%$ & 25.92 & 1.13 & 0.82 & 24.02 & {$[90]$} \\
\hline & Reference & 24.84 & 1.03 & 0.77 & 19.66 & \\
\hline
\end{tabular}

additives to alleviate either extrinsic or intrinsic negative impacts in OIPSCs.

Acknowledgements The authors would like to thank the department of Industrial Chemistry and Sustainable Energy Center of Excellence of Addis Ababa Science and Technology University (AASTU) for financial and infrastructure support to this work.
Open Access This article is licensed under a Creative Commons Attribution 4.0 International License, which permits use, sharing, adaptation, distribution and reproduction in any medium or format, as long as you give appropriate credit to the original author(s) and the source, provide a link to the Creative Commons licence, and indicate if changes were made. The images or other third party material in this article are included in the article's Creative Commons licence, unless indicated otherwise in a credit line to the material. If material is not included in 
the article's Creative Commons licence and your intended use is not permitted by statutory regulation or exceeds the permitted use, you will need to obtain permission directly from the copyright holder. To view a copy of this licence, visit http://creativecommons.org/licenses/by/4.0/.

\section{References}

1. Yoshikawa, K., Yoshida, W., Irie, T., Kawasaki, H., Konishi, K., Ishibashi, H., Asatani, T., Adachi, D., Kanematsu, M., Uzu, H., Yamamoto, K.: Exceeding conversion efficiency of $26 \%$ by heterojunction interdigitated back contact solar cell with thin film Si technology. Sol. Energy Mater. Sol. Cells. 173, 37-42 (2017). https://doi.org/10.1016/j.solmat.2017.06.024

2. Benamar, E., Rami, M., Fahoume, M., Chraibi, F., Ennaoui, A.: Electrodeposited cadmium selenide films for solar cells. Ann. Chim. Sci. des Mater. 23, 369-372 (1998). https://doi.org/10. 1016/S0151-9107(98)80094-9

3. Bonnet, D., Meyers, P.: Cadmium-telluride - Material for thin film solar cells. J. Mater. Res. 13, 2740-2753 (1998). https://doi. org/10.1557/JMR.1998.0376

4. Vasekar, P.S., Jahagirdar, A.H., Dhere, N.G.: Photovoltaic characterization of Copper-Indium-Gallium Sulfide $\left(\mathrm{CIGS}_{2}\right)$ solar cells for lower absorber thicknesses. Thin Solid Films 518, 1788-1790 (2010). https://doi.org/10.1016/j.tsf.2009.09.033

5. Stuckelberger, M., Biron, R., Wyrsch, N., Haug, F.J., Ballif, C.: Progress in solar cells from hydrogenated amorphous silicon. Renew. Sustain. Energy Rev. 76, 1497-1523 (2017). https://doi. org/10.1016/j.rser.2016.11.190

6. Joël Tchognia Nkuissi, H., Kouadio Konan, F., Hartiti, B., Ndjaka, J.-M.: Toxic materials used in thin film photovoltaics and their impacts on environment. In: Reliability and Ecological Aspects of Photovoltaic Modules. pp. 1-18 (2020)

7. Regan, B.O., Gratzel, M.: A low-cost, high-efficiency solar cell based on dyes-sensitized collodial $\mathrm{TiO}_{2}$ films. Nature 353, 737740 (1991). https://doi.org/10.1038/353737a0

8. Bernède, J.C.: Organic photovoltaic cells: History, principle and techniques. J. Chil. Chem. Soc. 53, 1549-1564 (2008). https:// doi.org/10.4067/S0717-97072008000300001

9. Jørgensen, M., Norrman, K., Krebs, F.C.: Stability/degradation of polymer solar cells. Sol. Energy Mater. Sol. Cells. 92, 686-714 (2008). https://doi.org/10.1016/j.solmat.2008.01.005

10. Shirakawa, H.: The discovery of polyacetylene film: The dawning of an era of conducting polymers. Synth. Met. 125, 3-10 (2002). https://doi.org/10.1016/s0379-6779(01)00507-0

11. Liu, Q., Jiang, Y., Jin, K., Qin, J., Xu, J., Li, W., Xiong, J., Liu, J., Xiao, Z., Sun, K., Yang, S., Zhang, X., Ding, L.: 18\% Efficiency organic solar cells. Sci. Bull. 65, 272-275 (2020). https://doi.org/ 10.1016/j.scib.2020.01.001

12. Kojima, A., Teshima, K., Shirai, Y., Miyasaka, T.: Organo-metal halide perovskites as visible-light sensitizers for photovoltaic cells. J. Am. Chem. Soc. 131, 6050-6051 (2009). https://doi. org/10.1021/ja809598r

13. Eperon, G.E., Stranks, S.D., Menelaou, C., Johnston, M.B., Herz, L.M., Snaith, H.J.: Formamidinium lead trihalide: A broadly tunable perovskite for efficient planar heterojunction solar cells. Energy Environ. Sci. 7, 982-988 (2014). https://doi.org/10.1039/ c3ee43822h

14. Green, M.A., Ho-Baillie, A., Snaith, H.J.: The emergence of perovskite solar cells. Nat. Photonics. 8, 506-514 (2014). https://doi. org/10.1038/nphoton.2014.134

15. Ziffer, M.E., Mohammed, J.C., Ginger, D.S.: Electroabsorption spectroscopy measurements of the exciton binding energy, electron-hole reduced effective mass, and band gap in the perovskite
$\mathrm{CH}_{3} \mathrm{NH}_{3} \mathrm{PbI}_{3}$. ACS Photonics 3, 1060-1068 (2016). https://doi. org/10.1021/acsphotonics.6b00139

16. Yang, W.S., Park, B.W., Jung, E.H., Jeon, N.J., Kim, Y.C., Lee, D.U., Shin, S.S., Seo, J., Kim, E.K., Noh, J.H., Seok, S. Il: Iodide management in formamidinium-lead-halide-based perovskite layers for efficient solar cells. Science (80-. ). 356, 1376-1379 (2017). https://doi.org/10.1126/science.aan2301

17. Giorgi, G., Fujisawa, J.I., Segawa, H., Yamashita, K.: Small photocarrier effective masses featuring ambipolar transport in methylammonium lead iodide perovskite: A density functional analysis. J. Phys. Chem. Lett. 4, 4213-4216 (2013). https://doi. org/10.1021/jz4023865

18. NREL: Best research-cell efficiencies, https://www.nrel.gov/pv/ assets/pdfs/best-research-cell-efficiencies.20200104.pdf

19. Olaleru, S.A., Kirui, J.K., Wamwangi, D., Roro, K.T., Mwakikunga, B.: Perovskite solar cells: the new epoch in photovoltaics. Sol. Energy. 196, 295-309 (2020). https://doi.org/10.1016/j.solen er.2019.12.025

20. Park, N.G.: Research direction toward scalable, stable, and high efficiency perovskite solar cells. Adv. Energy Mater. 10, 1903106 (2019). https://doi.org/10.1002/aenm.201903106

21. Baumann, A., Väth, S., Rieder, P., Heiber, M.C., Tvingstedt, K., Dyakonov, V.: Identification of trap states in perovskite solar cells. J. Phys. Chem. Lett. 6, 2350-2354 (2015). https://doi.org/ 10.1021/acs.jpclett.5b00953

22. Fan, R., Zhou, W., Huang, Z., Zhou, H.: Defect suppression and passivation for perovskite solar cells: from the birth to the lifetime operation. EnergyChem. 2, 100032 (2020). https://doi.org/ 10.1016/j.enchem.2020.100032

23. Wu, X., Trinh, M.T., Niesner, D., Zhu, H., Norman, Z., Owen, J.S., Yaffe, O., Kudisch, B.J., Zhu, X.Y.: Trap states in lead iodide perovskites. J. Am. Chem. Soc. 137, 2089-2096 (2015). https://doi.org/10.1021/ja512833n

24. Mahmud, M.A., Elumalai, N.K., Upama, M.B., Wang, D., Gonçales, V.R., Wright, M., Xu, C., Haque, F., Uddin, A.: Passivation of interstitial and vacancy mediated trap-states for efficient and stable triple-cation perovskite solar cells. J. Power Sources. 383, 59-71 (2018). https://doi.org/10.1016/j.jpowsour.2018.02.030

25. Berdiyorov, G.R., Madjet, M.E., El-Mellouhi, F., Peeters, F.M.: Effect of crystal structure on the electronic transport properties of the organometallic perovskite $\mathrm{CH}_{3} \mathrm{NH}_{3} \mathrm{PbI}_{3}$. Sol. Energy Mater. Sol. Cells. 148, 60-66 (2016). https://doi.org/10.1016/j.solmat. 2015.09.006

26. Varadwaj, P.R., Varadwaj, A., Marques, H.M., Yamashita, K.: Significance of hydrogen bonding and other noncovalent interactions in determining octahedral tilting in the $\mathrm{CH} 3 \mathrm{NH} 3 \mathrm{PbI} 3$ hybrid organic-inorganic halide perovskite solar cell semiconductor. Sci. Rep. 9, 1-29 (2019). https://doi.org/10.1038/ s41598-018-36218-1

27. Brivio, F., Frost, J.M., Skelton, J.M., Jackson, A.J., Weber, O.J., Weller, M.T., Goñi, A.R., Leguy, A.M.A., Barnes, P.R.F., Walsh, A.: Lattice dynamics and vibrational spectra of the orthorhombic, tetragonal, and cubic phases of methylammonium lead iodide. Phys. Rev. B - Condens. Matter Mater. Phys. 92, 144308 (2015). https://doi.org/10.1103/PhysRevB.92.144308

28. Wu, T., Wang, Y., Dai, Z., Cui, D., Wang, T., Meng, X., Bi, E., Yang, X., Han, L.: Efficient and stable CsPbI3 solar cells via regulating lattice distortion with surface organic terminal groups. Adv. Mater. 31, 1900605 (2019). https://doi.org/10.1002/adma. 201900605

29. Wang, F., Ye, Z., Sarvari, H., Park, S.M., Abtahi, A., Graham, K., Zhao, Y., Wang, Y., Chen, Z.D., Li, S.: Humidity-insensitive fabrication of efficient perovskite solar cells in ambient air. J. Power Sources. 412, 359-365 (2019). https://doi.org/10.1016/j. jpowsour.2018.11.013 
30. Kumar, Y., Regalado-Pérez, E., Ayala, A.M., Mathews, N.R., Mathew, X.: Effect of heat treatment on the electrical properties of perovskite solar cells. Sol. Energy Mater. Sol. Cells. 157, 10-17 (2016). https://doi.org/10.1016/j.solmat.2016.04.055

31. Zhang, H., Qiao, X., Shen, Y., Wang, M.: Effect of temperature on the efficiency of organometallic perovskite solar cells. J. Energy Chem. 24, 729-735 (2015). https://doi.org/10.1016/j. jechem.2015.10.007

32. Zheng, H., Liu, G., Zhang, C., Zhu, L., Alsaedi, A., Hayat, T., Pan, X., Dai, S.: The influence of perovskite layer and hole transport material on the temperature stability about perovskite solar cells. Sol. Energy. 159, 914-919 (2018). https://doi.org/10. 1016/j.solener.2017.09.039

33. Mesquita, I., Andrade, L., Mendes, A.: Effect of relative humidity during the preparation of perovskite solar cells: Performance and stability. Sol. Energy. 199, 474-483 (2020). https://doi.org/10. 1016/j.solener.2020.02.052

34. Dong, X., Fang, X., Lv, M., Lin, B., Zhang, S., Wang, Y., Yuan, N., Ding, J.: Method for improving illumination instability of organic-inorganic halide perovskite solar cells. Sci. Bull. 61, 236-244 (2016). https://doi.org/10.1007/s11434-016-0994-1

35. Lee, J.W., Bae, S.H., De Marco, N., Hsieh, Y.T., Dai, Z., Yang, Y.: The role of grain boundaries in perovskite solar cells. Mater. Today Energy. 7, 149-160 (2018). https://doi.org/10.1016/j. mtener.2017.07.014

36. Wang, S., Sina, M., Parikh, P., Uekert, T., Shahbazian, B., Devaraj, A., Meng, Y.S.: Role of 4-tert-butylpyridine as a hole transport layer morphological controller in perovskite solar cells. Nano Lett. 16, 5594-5600 (2016). https://doi.org/10.1021/acs. nanolett.6b02158

37. Urieta-Mora, J., García-Benito, I., Molina-Ontoria, A., Martín, N.: Hole transporting materials for perovskite solar cells: a chemical approach. Chem. Soc. Rev. 47, 8541-8571 (2018). https://doi.org/10.1039/c8cs00262b

38. Li, X., Fu, S., Liu, S., Wu, Y., Zhang, W., Song, W., Fang, J.: Suppressing the ions-induced degradation for operationally stable perovskite solar cells. Nano Energy 64, 103962 (2019). https://doi.org/10.1016/j.nanoen.2019.103962

39. Han, Y., Meyer, S., Dkhissi, Y., Weber, K., Pringle, J.M., Bach, U., Spiccia, L., Cheng, Y.B.: Degradation observations of encapsulated planar $\mathrm{CH} 3 \mathrm{NH} 3 \mathrm{PbI} 3$ perovskite solar cells at high temperatures and humidity. J. Mater. Chem. A. 3, 8139-8147 (2015). https://doi.org/10.1039/c5ta00358j

40. Chun-Ren Ke, J., Walton, A.S., Lewis, D.J., Tedstone, A., O'Brien, P., Thomas, A.G., Flavell, W.R.: In situ investigation of degradation at organometal halide perovskite surfaces by X-ray photoelectron spectroscopy at realistic water vapour pressure. Chem. Commun. 53, 5231-5234 (2017). https://doi.org/10.1039/ c7cc01538k

41. Gujar, T.P., Unger, T., Schönleber, A., Fried, M., Panzer, F., Van Smaalen, S., Köhler, A., Thelakkat, M.: The role of PbI2 in $\mathrm{CH} 3 \mathrm{NH} 3 \mathrm{PbI} 3$ perovskite stability, solar cell parameters and device degradation. Phys. Chem. Chem. Phys. 20, 605-614 (2017). https://doi.org/10.1039/c7cp04749e

42. Li, T., Pan, Y., Wang, Z., Xia, Y., Chen, Y., Huang, W.: Additive engineering for highly efficient organic-inorganic halide perovskite solar cells: Recent advances and perspectives. J. Mater. Chem. A. 5, 12602-12652 (2017). https://doi.org/10.1039/c7ta0 $1798 \mathrm{~g}$

43. Li, S., Ma, R.: Enhanced photovoltaic performance and stability of planar perovskite solar cells by introducing dithizone. Sol. Energy Mater. Sol. Cells. 206, 290 (2020). https://doi.org/10. 1016/j.solmat.2019.110290

44. Liu, Z., Ono, L.K., Qi, Y.: Additives in metal halide perovskite films and their applications in solar cells. J. Energy Chem. 46, 215-228 (2020). https://doi.org/10.1016/j.jechem.2019.11.008
45. Zhu, M., Li, C., Li, B., Zhang, J., Sun, Y., Guo, W., Zhou, Z., Pang, S., Yan, Y.: Interaction engineering in organic-inorganic hybrid perovskite solar cells. Mater. Horizons. 7, 2208-2236 (2020). https://doi.org/10.1039/d0mh00745e

46. Ha, S.R., Jeong, W.H., Liu, Y., Oh, J.T., Bae, S.Y., Lee, S., Kim, J.W., Bandyopadhyay, S., Jeong, H.I., Kim, J.Y., Kim, Y., Song, M.H., Park, S.H., Stranks, S.D., Lee, B.R., Friend, R.H., Choi, H.: Molecular aggregation method for perovskite-fullerene bulk heterostructure solar cells. J. Mater. Chem. A. 8, 1326-1334 (2020). https://doi.org/10.1039/c9ta11854c

47. Rolston, N., Printz, A.D., Tracy, J.M., Weerasinghe, H.C., Vak, D., Haur, L.J., Priyadarshi, A., Mathews, N., Slotcavage, D.J., McGehee, M.D., Kalan, R.E., Zielinski, K., Grimm, R.L., Tsai, H., Nie, W., Mohite, A.D., Gholipour, S., Saliba, M., Grätzel, M., Dauskardt, R.H.: Effect of cation composition on the mechanical stability of perovskite solar cells. Adv. Energy Mater. 8, 1702116 (2017). https://doi.org/10.1002/aenm.201702116

48. Chae, S., Yi, A., Kim, H.J.: Molecular engineering of a conjugated polymer as a hole transporting layer for versatile $\mathrm{p}-\mathrm{i}-\mathrm{n}$ perovskite solar cells. Mater. Today Energy. 14, 100341 (2019). https://doi.org/10.1016/j.mtener.2019.100341

49. Bakr, Z.H., Wali, Q., Fakharuddin, A., Schmidt-Mende, L., Brown, T.M., Jose, R.: Advances in hole transport materials engineering for stable and efficient perovskite solar cells. Nano Energy 34, 271-305 (2017). https://doi.org/10.1016/j.nanoen. 2017.02.025

50. Hou, F., Han, C., Isabella, O., Yan, L., Shi, B., Chen, J., An, S., Zhou, Z., Huang, W., Ren, H., Huang, Q., Hou, G., Chen, X., Li, Y., Ding, Y., Wang, G., Wei, C., Zhang, D., Zeman, M., Zhao, Y., Zhang, X.: Inverted pyramidally-textured PDMS antireflective foils for perovskite/silicon tandem solar cells with flat top cell. Nano Energy 56, 234-240 (2019). https://doi.org/10.1016/j. nanoen.2018.11.018

51. Wu, X., Zhang, L., Xu, Z., Olthof, S., Ren, X., Liu, Y., Yang, D., Gao, F., Liu, S.: Efficient perovskite solar cellsviasurface passivation by a multifunctional small organic ionic compound. J. Mater. Chem. A. 8, 8313-8322 (2020). https://doi.org/10.1039/ d0ta02222e

52. Zhang, W., Li, Y., Liu, X., Tang, D., Li, X., Yuan, X.: Ethyl acetate green antisolvent process for high-performance planar low-temperature $\mathrm{SnO}_{2}$-based perovskite solar cells made in ambient air. Chem. Eng. J. 379, 122298 (2020). https://doi.org/10. 1016/j.cej.2019.122298

53. Meng, Z., Guo, D., Yu, J., Fan, K.: Investigation of $\mathrm{Al} 2 \mathrm{O} 3$ and $\mathrm{ZrO} 2$ spacer layers for fully printable and hole-conductor-free mesoscopic perovskite solar cells. Appl. Surf. Sci. 430, 632-638 (2018). https://doi.org/10.1016/j.apsusc.2017.05.018

54. Wu, T., Wu, J., Tu, Y., He, X., Lan, Z., Huang, M., Lin, J.: Solvent engineering for high-quality perovskite solar cell with an efficiency approaching 20\%. J. Power Sources. 365, 1-6 (2017). https://doi.org/10.1016/j.jpowsour.2017.08.074

55. Tombe, S., Adam, G., Heilbrunner, H., Apaydin, D.H., Ulbricht, C., Sariciftci, N.S., Arendse, C.J., Iwuoha, E., Scharber, M.C.: Optical and electronic properties of mixed halide $(\mathrm{X}=\mathrm{I}, \mathrm{Cl}, \mathrm{Br})$ methylammonium lead perovskite solar cells. J. Mater. Chem. C. 5, 1714-1723 (2017). https://doi.org/10.1039/c6tc04830g

56. Hartono, N.T.P., Sun, S., Gélvez-Rueda, M.C., Pierone, P.J., Erodici, M.P., Yoo, J., Wei, F., Bawendi, M., Grozema, F.C., Sher, M.J., Buonassisi, T., Correa-Baena, J.P.: The effect of structural dimensionality on carrier mobility in lead-halide perovskites. J. Mater. Chem. A. 7, 23949-23957 (2019). https://doi. org/10.1039/c9ta05241k

57. Lewis, D.J.: Deposition Techniques for Perovskite Solar Cells. In: Nanostructured Materials for Type III Photovoltaics. pp. 341-366. The Royal Society of Chemistry, UK (2018) 
58. Nouri, E., Mohammadi, M.R., Lianos, P.: Improving the stability of inverted perovskite solar cells under ambient conditions with graphene-based inorganic charge transporting layers. Carbon N. Y. 126, 208-214 (2018). https://doi.org/10.1016/j.carbon.2017. 10.015

59. Feria, D.N., Chang, C.Y., Mahesh, K.P.O., Hsu, C.L., Chao, Y.C.: Perovskite solar cells based on a perovskite film with improved film coverage. Synth. Met. 260, 1 (2020). https://doi.org/10. 1016/j.synthmet.2019.116283

60. Wang, S., Wang, A., Deng, X., Xie, L., Xiao, A., Li, C., Xiang, Y., Li, T., Ding, L., Hao, F.: Lewis acid/base approach for efficacious defect passivation in perovskite solar cells. J. Mater. Chem. A. 8, 12201-12225 (2020). https://doi.org/10.1039/d0ta03957h

61. Adam, G., Kaltenbrunner, M., Głowacki, E.D., Apaydin, D.H., White, M.S., Heilbrunner, H., Tombe, S., Stadler, P., Ernecker, B., Klampfl, C.W., Sariciftci, N.S., Scharber, M.C.: Solution processed perovskite solar cells using highly conductive PEDOT:PSS interfacial layer. Sol. Energy Mater. Sol. Cells. 157, 318-325 (2016). https://doi.org/10.1016/j.solmat.2016.05.011

62. Guo, X., Zhang, M., Ma, W., Zhang, S., Hou, J., Li, Y.: Effect of solvent additive on active layer morphologies and photovoltaic performance of polymer solar cells based on PBDTTT-C-T / PC71BM. RSC Adv. 6, 51924-51931 (2016). https://doi.org/ $10.1039 / \mathrm{c} 6 \mathrm{ra06020j}$

63. Liao, H.C., Ho, C.C., Chang, C.Y., Jao, M.H., Darling, S.B., $\mathrm{Su}$, W.F.: Additives for morphology control in high-efficiency organic solar cells. Mater. Today. 16, 326-336 (2013). https:// doi.org/10.1016/j.mattod.2013.08.013

64. Park, S.H., Jin, I.S., Ahn, H., Jung, J.W.: Non-halogenated additive engineering for morphology optimization in environmental-friendly solvent processed non-fullerene organic solar cells. Org. Electron. 86, 105893 (2020). https://doi.org/10.1016/j.orgel. 2020.105893

65. Nazim, M., Abdullah, Akhtar, M.S., Kim, E.B., Shin, H.S., Ameen, S.: Underlying effects of diiodooctane as additive on the performance of bulk heterojunction organic solar cells based small organic molecule of isatin-core moiety. Synth. Met. 261, 116304 (2020). https://doi.org/10.1016/j.synthmet.2020.116304

66. Carvalho, I.C., Barbosa, M.L., Costa, M.J.S., Longo, E., Cavalcante, L.S., Viana, V.G.F., Santos, R.S.: $\mathrm{TiO}_{2}$-based dye-sensitized solar cells prepared with bixin and norbixin natural dyes: Effect of 2,2'-bipyridine additive on the current and voltage. Optik (Stuttg). 218, 165236 (2020). https://doi.org/10.1016/j. ijleo.2020.165236

67. Zhang, L., Zhao, H., Yuan, J., Lin, B., Xing, Z., Meng, X., Ke, L., $\mathrm{Hu}, \mathrm{X} ., \mathrm{Ma}, \mathrm{W} .$, Yuan, Y.: Blade-coated efficient and stable largearea organic solar cells with optimized additive. Org. Electron. 83, 105771 (2020). https://doi.org/10.1016/j.orgel.2020.105771

68. Cheng, J., Zhang, L., Jiang, H., Yuan, D., Wang, Q., Cao, Y., Chen, J.: Investigation of halogen-free solvents towards highperformance additive-free non-fullerene organic solar cells. Org. Electron. 85, 105871 (2020). https://doi.org/10.1016/j.orgel. 2020.105871

69. Yu, R., Yao, H., Hong, L., Qin, Y., Zhu, J., Cui, Y., Li, S., Hou, J.: Design and application of volatilizable solid additives in nonfullerene organic solar cells. Nat. Commun. 9, 4645 (2018). https://doi.org/10.1038/s41467-018-07017-z

70. Liu, S., Guan, Y., Sheng, Y., Hu, Y., Rong, Y., Mei, A., Han, H.: A Review on Additives for Halide Perovskite Solar Cells (2019)

71. Yang, J., Chen, S., Xu, J., Zhang, Q., Liu, H., Liu, Z., Yuan, M.: A review on improving the quality of perovskite films in perovskite solar cells via the weak forces induced by additives. Appl. Sci. 9, 4393 (2019). https://doi.org/10.3390/app9204393

72. Xie, J., Yan, K., Zhu, H., Li, G., Wang, H., Zhu, H., Hang, P., Zhao, S., Guo, W., Ye, D., Shao, L., Guan, X., Ngai, T., Yu, X., $\mathrm{Xu}, \mathrm{J}$.: Identifying the functional groups effect on passivating perovskite solar cells. Sci. Bull. 65, 1726-1734 (2020). https:// doi.org/10.1016/j.scib.2020.05.031

73. Afroz, M.A., Gupta, R.K., Garai, R., Hossain, M., Tripathi, S.P., Iyer, P.K.: Crystallization and grain growth regulation through Lewis acid-base adduct formation in hot cast perovskite-based solar cells. Org. Electron. 74, 172-178 (2019). https://doi.org/ 10.1016/j.orgel.2019.07.007

74. González-Juárez, E., González-Quijano, D., Garcia-Gutierrez, D.F., Garcia-Gutierrez, D.I., Ibarra-Rodríguez, J., Sanchez, E.: Improving performance of perovskites solar cells using solvent engineering, via Lewis adduct of MAI-DMSO-PbI ${ }_{2} \mathrm{i}$ and incorporation of imidazolium cation. J. Alloys Compd. 817, 153076 (2020). https://doi.org/10.1016/j.jallcom.2019.153076

75. Hamill, J.C., Schwartz, J., Loo, Y.L.: Influence of Solvent Coordination on Hybrid Organic-Inorganic Perovskite Formation. ACS Energy Lett. 3, 92-97 (2018). https://doi.org/10.1021/acsen ergylett.7b01057

76. Wu, Y., Wang, Y., Duan, J., Yang, X., Zhang, J., Liu, L., Tang, Q.: Cluster effect of additives in precursors for inorganic perovskites solar cells. Electrochim. Acta. 331, 135379 (2020). https:// doi.org/10.1016/j.electacta.2019.135379

77. Wang, M., Cao, F., Deng, K., Li, L.: Adduct phases induced controlled crystallization for mixed-cation perovskite solar cells with efficiency over $21 \%$. Nano Energy 63, 103867 (2019). https:// doi.org/10.1016/j.nanoen.2019.103867

78. Zhou, X., Kong, F., Sun, Y., Huang, Y., Zhang, X., Ghadari, R.: Dopant-free benzothiadiazole bridged hole transport materials for highly stable and efficient perovskite solar cells. Dye. Pigment. 173, 107954 (2020). https://doi.org/10.1016/j.dyepig. 2019. 107954

79. Wang, H., Zhang, X., Huang, T., Lu, Z., Gao, F., Shi, Z., Zhou, L., Li, R., Tang, G.: Enhance the performance of ZnO-based perovskite solar cells under ambient conditions. Opt. Mater. (Amst) 89, 375-381 (2019). https://doi.org/10.1016/j.optmat.2019.01. 059

80. Wang, G., Wang, L., Qiu, J., Yan, Z., Tai, K., Yu, W., Jiang, X.: Fabrication of efficient formamidinium perovskite solar cells under ambient air via intermediate-modulated crystallization. Sol. Energy. 187, 147-155 (2019). https://doi.org/10.1016/j.solen er.2019.05.033

81. Hailegnaw, B., Adam, G., Wielend, D., Pedarnig, J.D., Sariciftci, N.S., Scharber, M.C.: Acetylacetone improves the performance of mixed halide perovskite solar cells. J. Phys. Chem. C. 123, 23807-23816 (2019). https://doi.org/10.1021/acs.jpcc.9b05058

82. Liang, P.W., Liao, C.Y., Chueh, C.C., Zuo, F., Williams, S.T., Xin, X.K., Lin, J., Jen, A.K.Y.: Additive enhanced crystallization of solution-processed perovskite for highly efficient planarheterojunction solar cells. Adv. Mater. 26, 3748-3754 (2014). https://doi.org/10.1002/adma.201400231

83. Li, Y., Shi, J., Zheng, J., Bing, J., Yuan, J., Cho, Y., Tang, S., Zhang, M., Yao, Y., Lau, C.F.J., Lee, D.S., Liao, C., Green, M.A., Huang, S., Ma, W., Ho-Baillie, A.W.Y.: Acetic acid assisted crystallization strategy for high efficiency and long-rerm stable perovskite solar cell. Adv. Sci. 7, 1903368 (2020). https:// doi.org/10.1002/advs.201903368

84. Cui, C., Xie, D., Lin, P., Hu, H., Che, S., Xiao, K., Wang, P., $\mathrm{Xu}, \mathrm{L}$., Yang, D., Yu, X.: Thioacetamide additive assisted crystallization of solution-processed perovskite films for high performance planar heterojunction solar cells. Sol. Energy Mater. Sol. Cells. 208, 110435 (2020). https://doi.org/10.1016/j.solmat.2020.110435

85. Zhang, Z., Fan, W., Wei, X., Zhang, L., Yang, Z., Wei, Z., Shen, T., Si, H., Qi, J.: Promoted performance of carbon based perovskite solar cells by environmentally friendly additives of $\mathrm{CH}_{3} \mathrm{COONH}_{4}$ and $\mathrm{Zn}\left(\mathrm{CH}_{3} \mathrm{COO}\right)_{2}$. J. Alloys Compd. 802, 694-703 (2019). https://doi.org/10.1016/j.jallcom.2019.06.161

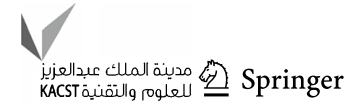


86. Li, Y., Zhang, Z., Zhou, Y., Xie, L., Gao, N., Lu, X., Gao, X., Gao, J., Shui, L., Wu, S., Liu, J.: Enhanced performance and stability of ambient-processed $\mathrm{CH}_{3} \mathrm{NH}_{3} \mathrm{PbI}_{3-\mathrm{x}}(\mathrm{SCN})_{\mathrm{x}}$ planar perovskite solar cells by introducing ammonium salts. Appl. Surf. Sci. 513, 145790 (2020). https://doi.org/10.1016/j.apsusc. 2020.145790

87. Lu, H., Krishna, A., Zakeeruddin, S.M., Grätzel, M., Hagfeldt, A.: Compositional and interface engineering of organic-inorganic lead halide perovskite solar cells. iScience. 23, 101359 (2020). https://doi.org/10.1016/j.isci.2020.101359

88. Li, X., Yang, J., Jiang, Q., Chu, W., Zhang, D., Zhou, Z., Ren, Y., Xin, J.: Enhanced photovoltaic performance and stability in mixed-cation perovskite solar cells via compositional modulation. Electrochim. Acta. 247, 460-467 (2017). https://doi.org/ 10.1016/j.electacta.2017.07.040

89. Albero, J., Asiri, A.M., García, H.: Influence of the composition of hybrid perovskites on their performance in solar cells. J. Mater. Chem. A. 4, 4353-4364 (2016). https://doi.org/10. 1039/c6ta00334f

90. Kim, M., Kim, G.H., Lee, T.K., Choi, I.W., Choi, H.W., Jo, Y., Yoon, Y.J., Kim, J.W., Lee, J., Huh, D., Lee, H., Kwak, S.K., Kim, J.Y., Kim, D.S.: Methylammonium chloride induces intermediate phase stabilization for efficient perovskite solar cells. Joule. 3, 2179-2192 (2019). https://doi.org/10.1016/j. joule.2019.06.014

91. Lee, K., Cho, K.H., Ryu, J., Yun, J., Yu, H., Lee, J., Na, W., Jang, J.: Low-cost and efficient perovskite solar cells using a surfactant-modified polyaniline:poly(styrenesulfonate) hole transport material. Electrochim. Acta. 224, 600-607 (2017). https://doi.org/10.1016/j.electacta.2016.12.103

92. Chang, C.Y., Chang, Y.C., Huang, W.K., Lee, K.T., Cho, A.C., Hsu, C.C.: Enhanced performance and stability of semitransparent perovskite solar cells using solution-processed thiolfunctionalized cationic surfactant as cathode buffer layer. Chem. Mater. 27, 7119-7127 (2015). https://doi.org/10.1021/ acs.chemmater.5b03137

93. Hong, J., Kim, H., Hwang, I.: Defect site engineering for charge recombination and stability via polymer surfactant incorporation with an ultra-small amount in perovskite solar cells. Org. Electron. 73, 87-93 (2019). https://doi.org/10. 1016/j.orgel.2019.06.003

94. Gao, F., Zhao, Y., Zhang, X., You, J.: Recent progresses on defect passivation toward efficient perovskite solar cells. Adv. Energy Mater. 10, 1902650 (2020). https://doi.org/10.1002/ aenm.201902650

95. Liao, K., Li, C., Xie, L., Yuan, Y., Wang, S., Cao, Z., Ding, L., Hao, F.: Hot-casting large-grain perovskite film for efficient solar cells: Film formation and device performance. Nano-Micro Lett. 12, 156 (2020). https://doi.org/10.1007/ s40820-020-00494-2

96. Guo, F., Li, X., Jiang, X., Zhao, X., Guo, C., Rao, Z.: Characteristics and toxic dye adsorption of magnetic activated carbon prepared from biomass waste by modified one-step synthesis. Colloids Surf. A Physicochem. Eng. Asp. 1, 3-46 (2018). https:// doi.org/10.1016/j.colsurfa.2018.06.061

97. Chen, B., Rudd, P.N., Yang, S., Yuan, Y., Huang, J.: Imperfections and their passivation in halide perovskite solar cells. Chem. Soc. Rev. 48, 3842-3867 (2019). https://doi.org/10.1039/c8cs0 $0853 \mathrm{a}$

98. Lee, M.S., Sarwar, S., Park, S., Asmat, U., Thuy, D.T., Han, C.H., Ahn, S.J., Jeong, I., Hong, S.: Efficient defect passivation of perovskite solar cells: via stitching of an organic bidentate molecule. Sustain. Energy Fuels. 4, 3318-3325 (2020). https:// doi.org/10.1039/c9se01041f

99. Guo, P., Ye, Q., Yang, X., Zhang, J., Xu, F., Shchukin, D., Wei, B., Wang, H.: Surface \& grain boundary co-passivation by fluorocarbon based bifunctional molecules for perovskite solar cells with efficiency over 21\%. J. Mater. Chem. A. 7, 2497-2506 (2019). https://doi.org/10.1039/c8ta11524a

100. Duenas, S., Perez, E., Castan, H., Garcia, H., Bailon, L.: The role of defects in solar cells: Control and detection defects in solar cells. Proc. 2013 Spanish Conf. Electron Devices, CDE 2013. 301-304 (2013). https://doi.org/10.1109/CDE.2013.6481402

101. Yonenaga, I., Ohno, Y., Taishi, T., Tokumoto, Y.: Recent knowledge of strength and dislocation mobility in wide band-gap semiconductors. Phys. B Condens. Matter. 404, 4999-5001 (2009). https://doi.org/10.1016/j.physb.2009.08.196

102. Queisser, H.J., Haller, E.E.: Defects in semiconductors: Some fatal, some vital. Science 281, 945-950 (1998)

103. Chen, Y., Zhou, H.: Defects chemistry in high-efficiency and stable perovskite solar cells. J. Appl. Phys. 128, 1 (2020). https:// doi.org/10.1063/5.0012384

104. Montoya, D.M., Pérez-Gutiérrez, E., Barbosa-Garcia, O., Bernal, W., Maldonado, J.L., Percino, M.J., Meneses, M.A., Cerón, M.: Defects at the interface electron transport layer and alternative counter electrode, their impact on perovskite solar cells performance. Sol. Energy. 195, 610-617 (2020). https://doi.org/10. 1016/j.solener.2019.11.098

105. Agiorgousis, M.L., Sun, Y.Y., Zeng, H., Zhang, S.: Strong covalency-induced recombination centers in perovskite solar cell material $\mathrm{CH}_{3} \mathrm{NH}_{3} \mathrm{PbI}_{3}$. J. Am. Chem. Soc. 136, 14570-14575 (2014). https://doi.org/10.1021/ja5079305

106. Aidarkhanov, D., Ren, Z., Lim, C.K., Yelzhanova, Z., Nigmetova, G., Taltanova, G., Baptayev, B., Liu, F., Cheung, S.H., Balanay, M., Baumuratov, A., Djurišić, A.B., So, S.K., Surya, C., Prasad, P.N., Ng, A.: Passivation engineering for hysteresis-free mixed perovskite solar cells. Sol. Energy Mater. Sol. Cells. 215, 110648 (2020). https://doi.org/10.1016/j.solmat.2020.110648

107. Chen, B., Yang, M., Priya, S., Zhu, K.: Origin of J-V hysteresis in perovskite solar cells. J. Phys. Chem. Lett. 7, 905-917 (2016). https://doi.org/10.1021/acs.jpclett.6b00215

108. Yuan, Y., Bi, C., Xiao, Z., Huang, J., Shao, Y., Xiao, Z., Bi, C., Yuan, Y., Huang, J.: Origin and elimination of photocurrent hysteresis by fullerene passivation in $\mathrm{CH}_{3} \mathrm{NH}_{3} \mathrm{PbI}_{3}$. planar heterojunction solar cells. Nat Commun. 5, 1-7 (2014). https://doi. org/10.1038/ncomms6784

109. Song, T.-B., Zhou, H., Chen, C.-C., Yang, Y.: Under the spotlight: The organic-inorganic hybrid halide perovskite for optoelectronic applications. Nano Today 10,355-396 (2015). https:// doi.org/10.1016/j.nantod.2015.04.009

110. Yang, J., Siempelkamp, B.D., Liu, D., Kelly, T.L.: Investigation of $\mathrm{CH} 3 \mathrm{NH} 3 \mathrm{PbI} 3$ degradation rates and mechanisms in controlled humidity environments using in situ techniques. ACS Nano 9, 1955-1963 (2015). https://doi.org/10.1021/nn506864k

111. Huang, W., Manser, J.S., Kamat, P.V., Ptasinska, S.: Evolution of chemical composition, morphology, and photovoltaic efficiency of $\mathrm{CH}_{3} \mathrm{NH}_{3} \mathrm{PbI}_{3}$. perovskite under ambient conditions. Chem. Mater. 28, 303-311 (2016). https://doi.org/10.1021/acs.chemm ater.5b04122

112. Arias-Ramos, C.F., Kumar, Y., Abrego-Martínez, P.G., Hu, H.: Efficient and stable hybrid perovskite prepared at $60 \%$ relative humidity with a hydrophobic additive in anti-solvent. Sol. Energy Mater. Sol. Cells. 215, 1 (2020). https://doi.org/ 10.1016/j.solmat.2020.110625

113. Liu, P., Liu, Z., Qin, C., He, T., Li, B., Ma, L., Shaheen, K., Yang, J., Yang, H., Liu, H., Liu, K., Yuan, M.: High-performance perovskite solar cells based on passivating interfacial and intergranular defects. Sol. Energy Mater. Sol. Cells. 212, 110555 (2020). https://doi.org/10.1016/j.solmat.2020.110555

114. Wang, Z., Fan, P., Zhang, D., Yang, G., Yu, J.: Enhanced efficiency and stability of $\mathrm{p}-\mathrm{i}-\mathrm{n}$ perovskite solar cells using PMMA 
doped PTAA as hole transport layers. Synth. Met. 265, 116428 (2020). https://doi.org/10.1016/j.synthmet.2020.116428

115. Li, G., Wu, J., Song, J., Meng, C., Song, Z., Wang, X., Liu, X., Yang, Y., Wang, D., Lan, Z.: Excellent quinoline additive in perovskite toward to efficient and stable perovskite solar cells. J. Power Sources. 481, 228857 (2021). https://doi.org/ 10.1016/j.jpowsour.2020.228857

116. Wang, S., Li, H., Zhang, B., Guo, Z.: Perovskite solar cells based on the synergy between carbon electrodes and polyethylene glycol additive with excellent stability. Org. Electron. 83, 734 (2020). https://doi.org/10.1016/j.orgel.2020.105734

117. Lin, Y.H., Sakai, N., Da, P., Wu, J., Sansom, H.C., Ramadan, A.J., Mahesh, S., Liu, J., Oliver, R.D.J., Lim, J., Aspitarte, L., Sharma, K., Madhu, P.K., Morales-Vilches, A.B., Nayak, P.K., Bai, S., Gao, F., Grovenor, C.R.M., Johnston, M.B., Labram, J.G., Durrant, J.R., Ball, J.M., Wenger, B., Stannowski, B., Snaith, H.J.: A piperidinium salt stabilizes efficient metal-halide perovskite solar cells. Science (80-. ). 369, 96-102 (2020). https://doi.org/10.1126/science.aba1628

118. Jin, S., Wei, Y., Rong, B., Fang, Y., Zhao, Y., Guo, Q., Huang, Y., Fan, L., Wu, J.: Improving perovskite solar cells photovoltaic performance using tetrabutylammonium salt as additive. J. Power Sources. 450, 227623 (2020). https://doi.org/10.1016/j. jpowsour.2019.227623

119. Parveen, S., Obaidulla, S.M., Giri, P.K.: Growth kinetics of hybrid perovskite thin films on different substrates at elevated temperature and its direct correlation with the microstructure and optical properties. Appl. Surf. Sci. 530, 147224 (2020). https://doi.org/10.1016/j.apsusc.2020.147224

120. Nancollas, G.H., Purdie, N.: The kinetics of crystal growth. Q. Rev. Chem. Soc. 18, 1-20 (1964). https://doi.org/10.1039/ qr9641800001

121. Large-area perovskite solar cells: Yang, J., Zuo, C., Peng, Y., (Michael) Yang, Y., Yang, X., Ding, L. Sci. Bull. 65, 872-875 (2020). https://doi.org/10.1016/j.scib.2020.02.023

122. Meng, L., You, J., Yang, Y.: Addressing the stability issue of perovskite solar cells for commercial applications. Nat. Commun. 9, 5265 (2018). https://doi.org/10.1038/ s41467-018-07255-1

123. Mali, S.S., Patil, J.V., Arandiyan, H., Luque, R., Hong, C.K.: Stability of unstable perovskites: recent strategies for making stable perovskite solar cells. ECS J. Solid State Sci. Technol. 8, Q111-Q117 (2019). https://doi.org/10.1149/2.0201906jss

124. Zimmermann, I., Mosconi, E., Lee, X., Martineau, D., Narbey, S., Oswald, F., Grancini, G., Rolda, C.: One-year stable perovskite solar cells by 2D/3D interface engineering. Nat. Commun. 8, 15684 (2017). https://doi.org/10.1038/ncomms 15684

125. Shao, Y., Fang, Y., Huang, J., Cao, L., Mulligan, P., Dong, Q., Qiu, J.: Electron-hole diffusion lengths $>175 \mu \mathrm{m}$ in solutiongrown CH 3 NH 3 PbI 3 single crystals. Science (80-). 347, 967-970 (2015). https://doi.org/10.1126/science.aaa5760

126. Yan, X., Hu, S., Zhang, Y., Li, H., Sheng, C.: Methylammonium acetate as an additive to improve performance and eliminate $\mathrm{J}-\mathrm{V}$ hysteresis in 2D homologous organic-inorganic perovskite solar cells. Sol. Energy Mater. Sol. Cells. 191, 283-289 (2019). https:// doi.org/10.1016/j.solmat.2018.11.030

127. Zheng, H., Liu, D., Wang, Y., Yang, Y., Li, H., Zhang, T., Chen, H., Ji, L., Chen, Z., Li, S.: Synergistic effect of additives on 2D perovskite film towards efficient and stable solar cell. Chem. Eng. J. 389, 124266 (2020). https://doi.org/10.1016/j. cej.2020.124266

128. Chen, M., Li, P., Liang, C., Gu, H., Tong, W., Cheng, S., Li, W., Zhao, G., Shao, G.: Enhanced efficiency and stability of perovskite solar cells by $2 \mathrm{D}$ perovskite vapor-assisted interface optimization. J. Energy Chem. 45, 103-109 (2020). https://doi. org/10.1016/j.jechem.2019.10.006
129. Li, J., Wu, M., Yang, G., Zhang, D., Wang, Z., Zheng, D., Yu, J.: Bottom-up passivation effects by using $3 \mathrm{D} / 2 \mathrm{D}$ mix structure for high performance p-i-n perovskite solar cells. Sol. Energy. 205, 44-50 (2020). https://doi.org/10.1016/j.solener.2020.05.042

130. Yao, D., Mao, X., Wang, X., Yang, Y., Hoang, M.T., Du, A., Waclawik, E.R., Wilson, G.J., Wang, H.: The effect of ethyleneamine ligands enhancing performance and stability of perovskite solar cells. J. Power Sources. 463, 228210 (2020). https://doi.org/ 10.1016/j.jpowsour.2020.228210

131. Du, Y., Wu, J., Zhang, X., Zhu, Q., Zhang, M., Liu, X., Zou, Y., Wang, S., Sun, W.: Surface passivation using pyridinium iodide for highly efficient planar perovskite solar cells. J. Energy Chem. 52, 84-91 (2021). https://doi.org/10.1016/j.jechem.2020.04.049

132. Si, H., Xu, C., Ou, Y., Zhang, G., Fan, W., Xiong, Z., Kausar, A., Liao, Q., Zhang, Z., Sattar, A., Kang, Z., Zhang, Y.: Dual-passivation of ionic defects for highly crystalline perovskite. Nano Energy 68, 104320 (2020). https://doi.org/10.1016/j.nanoen. 2019.104320

133. Wali, Q., Iftikhar, F.J., Khan, M.E., Ullah, A., Iqbal, Y., Jose, R.: Advances in stability of perovskite solar cells. Org. Electron. 78, 105590 (2020). https://doi.org/10.1016/j.orgel.2019.105590

134. Mesquita, I., Andrade, L., Mendes, A.: Perovskite solar cells: materials, configurations and stability. Renew. Sustain. Energy Rev. 82, 2471-2489 (2018). https://doi.org/10.1016/j.rser.2017. 09.011

135. Jeng, J.Y., Chiang, Y.F., Lee, M.H., Peng, S.R., Guo, T.F., Chen, P., Wen, T.C.: $\mathrm{CH}_{3} \mathrm{NH}_{3} \mathrm{PbI}_{3}$. perovskite/fullerene planar-heterojunction hybrid solar cells. Adv. Mater. 25, 3727-3732 (2013). https://doi.org/10.1002/adma.201301327

136. Chowdhury, T.H., Kaneko, R., Kayesh, M.E., Akhtaruzzaman, M., Sopian, K. Bin, Lee, J.J., Islam, A.: Nanostructured NiOxas hole transport material for low temperature processed stable perovskite solar cells. Mater. Lett. 223, 109-111 (2018). https://doi. org/10.1016/j.matlet.2018.04.040

137. Sun, J., Lu, J., Li, B., Jiang, L., Chesman, A.S.R., Scully, A.D., Gengenbach, T.R., Cheng, Y.B., Jasieniak, J.J.: Inverted perovskite solar cells with high fill-factors featuring chemical bath deposited mesoporous $\mathrm{NiO}$ hole transporting layers. Nano Energy 49, 163-171 (2018). https://doi.org/10.1016/j.nanoen. 2018.04.026

138. Luo, C., Li, G., Chen, L., Dong, J., Yu, M., Xu, C., Yao, Y., Wang, M., Song, Q., Zhang, S.: Passivation of defects in inverted perovskite solar cells using an imidazolium-based ionic liquid. Sustain. Energy Fuels. 4, 3971-3978 (2020). https://doi.org/10. 1039/d0se00528b

139. Huang, D., Goh, T., Kong, J., Zheng, Y., Zhao, S., Xu, Z., Taylor, A.D.: Perovskite solar cells with a DMSO-treated PEDOT:PSS hole transport layer exhibit higher photovoltaic performance and enhanced durability. Nanoscale 9, 4236-4243 (2017). https://doi. org/10.1039/c6nr08375g

140. Kaltenbrunner, M., Adam, G., Głowacki, E.D., Drack, M. Schwödiauer, R., Leonat, L., Apaydin, D.H., Groiss, H., Scharber, M.C., White, M.S., Sariciftci, N.S., Bauer, S.: Flexible high power-per-weight perovskite solar cells with chromium oxidemetal contacts for improved stability in air. Nat. Mater. 14, 1032-1039 (2015). https://doi.org/10.1038/nmat4388

141. Zhou, X., Hu, M., Liu, C., Zhang, L., Zhong, X., Li, X., Tian, Y., Cheng, C., Xu, B.: Synergistic effects of multiple functional ionic liquid-treated PEDOT:PSS and less-ion-defects S-acetylthiocholine chloride-passivated perovskite surface enabling stable and hysteresis-free inverted perovskite solar cells with conversion efficiency over 2. Nano Energy 63, 103866 (2019). https://doi. org/10.1016/j.nanoen.2019.103866

142. Zheng, X., Hou, Y., Bao, C., Yin, J., Yuan, F., Huang, Z., Song, K., Liu, J., Troughton, J., Gasparini, N., Zhou, C., Lin, Y., Xue, D.J., Chen, B., Johnston, A.K., Wei, N., Hedhili, M.N., Wei, 
M., Alsalloum, A.Y., Maity, P., Turedi, B., Yang, C., Baran, D., Anthopoulos, T.D., Han, Y., Lu, Z.H., Mohammed, O.F., Gao, F., Sargent, E.H., Bakr, O.M.: Managing grains and interfaces via ligand anchoring enables $22.3 \%$-efficiency inverted perovskite solar cells. Nat. Energy. 5, 131-140 (2020). https://doi.org/10. 1038/s41560-019-0538-4

143. Choi, M.J., Lee, Y.S., Cho, I.H., Kim, S.S., Kim, D.H., Kwon, S.N., Na, S.I.: Functional additives for high-performance inverted planar perovskite solar cells with exceeding $20 \%$ efficiency: selective complexation of organic cations in precursors. Nano Energy 71, 104639 (2020). https://doi.org/10.1016/j.nanoen. 2020.104639

144. Su, L., Xiao, Y., Han, G., Lu, L., Li, H., Zhu, M.: Performance enhancement of perovskite solar cells using trimesic acid additive in the two-step solution method. J. Power Sources. 426, 11-15 (2019). https://doi.org/10.1016/j.jpowsour.2019.04.024

145. Yao, Z., Qu, D., Guo, Y., Huang, H.: Grain boundary regulation of flexible perovskite solar cells via a polymer alloy additive. Org. Electron. 70, 205-210 (2019). https://doi.org/10.1016/j. orgel.2019.04.029

146. Ma, S., Liu, X., Wu, Y., Tao, Y., Ding, Y., Cai, M., Dai, S., Liu, X., Alsaedi, A., Hayat, T.: Efficient and flexible solar cells with improved stability through incorporation of a multifunctional small molecule at PEDOT:PSS/perovskite interface. Sol. Energy Mater. Sol. Cells. 208, 110379 (2020). https://doi.org/10.1016/j. solmat.2019.110379

147. Zhu, K., Cong, S., Lu, Z., Lou, Y., He, L., Li, J., Ding, J., Yuang, N., Rümmeli, M.H., Zou, G.: Enhanced perovskite solar cell performance via defect passivation with ethylamine alcohol chlorides additive. J. Power Sources. 428, 82-87 (2019). https://doi. org/10.1016/j.jpowsour.2019.04.056

148. Wang, R., Xue, J., Meng, L., Lee, J.W., Zhao, Z., Sun, P., Cai, L., Huang, T., Wang, Z., Wang, Z.K., Duan, Y., Yang, J.L., Tan, S., Yuan, Y., Huang, Y., Yang, Y.: Caffeine improves the performance and thermal stability of perovskite solar cells. Joule. 3, 1464-1477 (2019). https://doi.org/10.1016/j.joule.2019.04.005

149. Xiong, S., Hao, T., Sun, Y., Yang, J., Ma, R., Wang, J., Gong, S., Liu, X., Ding, L., Fahlman, M., Bao, Q.: Defect passivation by nontoxic biomaterial yields $21 \%$ efficiency perovskite solar cells. J. Energy Chem. 55, 265-271 (2021). https://doi.org/10.1016/j. jechem.2020.06.061

150. Zhang, X., Wu, J., Du, Y., Li, Z., Chen, Q., Zhang, Z., Rong, B., Wang, D., Li, G., Sun, W.: Interfacial defect passivation by chenodeoxycholic acid for efficient and stable perovskite solar cells. J. Power Sources. 472, 228502 (2020). https://doi.org/10. 1016/j.jpowsour.2020.228502

151. Xin, D., Tie, S., Zheng, X., Zhu, J., Zhang, W.H.: Defect passivation through electrostatic interaction for high performance flexible perovskite solar cells. J. Energy Chem. 46, 173-177 (2020). https://doi.org/10.1016/j.jechem.2019.11.015

152. Umeyama, T., Imahori, H.: A chemical approach to perovskite solar cells: control of electron-transporting mesoporous $\mathrm{TiO} 2$ and utilization of nanocarbon materials. Dalt. Trans. 1, 1561515627 (2017). https://doi.org/10.1039/C7DT02421E

153. Xie, J., Zhou, Z., Qiao, H., Chen, M., Wang, L., Yang, S., Hou, Y., Yang, H.: Modulating MAPbI3 perovskite solar cells by amide molecules: crystallographic regulation and surface passivation. J. Energy Chem. 56, 179-185 (2021). https://doi.org/ 10.1016/j.jechem.2020.07.050

154. Nishihara, Y., Onozawa-Komatsuzaki, N., Zou, X., Marumoto, K., Chikamatsu, M., Yoshida, Y.: Effect of passivation on the interface between perovskite and donor-acceptor copolymerbased hole-transport Layer in perovskite solar cells. Chem. Lett. 49, 1341-1344 (2020). https://doi.org/10.1246/cl.200497

155. Wang, Y., Yang, Y., Han, D.W., Yang, Q.F., Yuan, Q., Li, H.Y., Yang, Y., Zhou, D.Y., Feng, L.: Amphoteric imidazole doping induced large-grained perovskite with reduced defect density for high performance inverted solar cells. Sol. Energy Mater. Sol. Cells. 212, 110553 (2020). https://doi.org/10.1016/j.solmat.2020. 110553

156. Sonmezoglu, S., Akin, S.: Suppression of the interface-dependent nonradiative recombination by using 2 -methylbenzimidazole as interlayer for highly efficient and stable perovskite solar cells. Nano Energy 76, 105127 (2020). https://doi.org/10.1016/j. nanoen.2020.105127

157. Zhang, Y., Grancini, G., Fei, Z., Shirzadi, E., Liu, X., Oveisi, E., Tirani, F.F., Scopelliti, R., Feng, Y., Nazeeruddin, M.K., Dyson, P.J.: Auto-passivation of crystal defects in hybrid imidazolium/ methylammonium lead iodide films by fumigation with methylamine affords high efficiency perovskite solar cells. Nano Energy 58, 105-111 (2019). https://doi.org/10.1016/j.nanoen.2019.01. 027

158. Li, W., Lai, X., Meng, F., Li, G., Wang, K., Kyaw, A.K.K., Sun, X.W.: Efficient defect-passivation and charge-transfer with interfacial organophosphorus ligand modification for enhanced performance of perovskite solar cells. Sol. Energy Mater. Sol. Cells. 211, 110527 (2020). https://doi.org/10.1016/j.solmat.2020. 110527

159. Wu, Z., Zhang, M., Liu, Y., Dou, Y., Kong, Y., Gao, L., Han, W., Liang, G., Zhang, X.L., Huang, F., Cheng, Y.B., Zhong, J.: Groups-dependent phosphines as the organic redox for point defects elimination in hybrid perovskite solar cells. J. Energy Chem. 54, 23-29 (2020). https://doi.org/10.1016/j.jechem.2020. 05.047

160. He, Q., Worku, M., Xu, L., Zhou, C., Lteif, S., Schlenoff, J.B., Ma, B.: Surface passivation of perovskite thin films by phosphonium halides for efficient and stable solar cells. J. Mater. Chem. A. 8, 2039-2046 (2020). https://doi.org/10.1039/c9ta12597c

161. Yang, J., Liu, C., Cai, C., Hu, X., Huang, Z., Duan, X., Meng, X., Yuan, Z., Tan, L., Chen, Y.: High-performance perovskite solar cells with excellent humidity and thermo-stability via fluorinated perylenediimide. Adv. Energy Mater. 9, 1900198 (2019). https:// doi.org/10.1002/aenm.201900198

162. Maaej, A., Bahri, M., Abid, Y., Jaidane, N., Lakhdar, Z.B., Lautié, A.: Raman study of low temperature phase transitions in the cubic perovskite $\mathrm{CH}_{3} \mathrm{NH}_{3} \mathrm{PbCl}_{3}$. Phase Transitions 64, 179-190 (1998). https://doi.org/10.1080/01411599808207997

163. Luo, D., Yu, L., Wang, H., Zou, T., Luo, L., Liu, Z., Lu, Z.: Cubic structure of the mixed halide perovskite $\mathrm{CH}_{3} \mathrm{NH}_{3} \mathrm{PbI}_{3-\mathrm{x}} \mathrm{Cl}_{\mathrm{x}}$ via thermal annealing. RSC Adv. 5, 85480-85485 (2015). https:// doi.org/10.1039/c5ra16516d

164. Wu, S., Zhang, J., Li, Z., Liu, D., Qin, M., Cheung, S.H., Lu, X., Lei, D., So, S.K., Zhu, Z., Jen, A.K.Y.: Modulation of defects and interfaces through alkylammonium interlayer for efficient inverted perovskite solar cells. Joule. 4, 1248-1262 (2020). https://doi.org/10.1016/j.joule.2020.04.001

165. Cahen, D., Hodes, G., Rosenwaks, Y., Gartsman, K., Mukhopadhyay, S., Henning, A., Kirmayer, S., Edri, E.: Why lead methylammonium tri-iodide perovskite-based solar cells require a mesoporous electron transporting scaffold (but not necessarily a hole conductor). Nano Lett. 14, 1000-1004 (2014)

166. Batch, U., Lupo, D.: Solid-state dye-sensitized mesoporous $\mathrm{TiO}_{2}$ solar cells with high photon-to-electron conversion efficiencies. Nature 395, 583-585 (1998). https://doi.org/10.1002/97804 70638859.conrr518

167. Jiang, H., Jiang, G., Xing, W., Xiong, W., Zhang, X., Wang, B., Zhang, H., Zheng, Y.: High current density and low hysteresis effect of planar perovskite solar cells via PCBM-doping and interfacial improvement. ACS Appl. Mater. Interfaces. 10, 29954-29964 (2018). https://doi.org/10.1021/acsami.8b06020

168. Hailegnaw, B., Adam, G., Heilbrunner, H., Apaydin, D.H., Ulbricht, C., Sariciftci, N.S., Scharber, M.C.: Inverted (p-i-n) 
perovskite solar cells using a low temperature processed TiOx interlayer. RSC Adv. 8, 24836-24846 (2018). https://doi.org/10. 1039/c8ra03993c

169. Zhang, L., Wu, B., Lin, S., Li, J.: Structures and properties of higher-degree aggregates of methylammonium iodide toward halide perovskite solar cells. Russ. J. Phys. Chem. A. 93, 2250-2255 (2019). https://doi.org/10.1134/S0036024419110360

170. Li, M., Li, N., Hu, W., Chen, G., Sasaki, S.I., Sakai, K., Ikeuchi, T., Miyasaka, T., Tamiaki, H., Wang, X.F.: Effects of cyclic tetrapyrrole rings of aggregate-forming chlorophyll derivatives as hole-transporting materials on performance of perovskite solar cells. ACS Appl. Energy Mater. 1, 9-16 (2018). https://doi.org/ 10.1021/acsaem.7b00018

171. Ye, T., Jin, S., Singh, R., Kumar, M., Chen, W., Wang, D., Zhang, X., Li, W., He, D.: Effects of solvent additives on the morphology and transport property of a perylene diimide dimer film in perovskite solar cells for improved performance. Sol. Energy. 201, 927-934 (2020). https://doi.org/10.1016/j.solener.2020.03. 062

172. Pham, N.D., Shang, J., Yang, Y., Hoang, M.T., Tiong, V.T., Wang, X., Fan, L., Chen, P., Kou, L., Wang, L., Wang, H.: Alkaline-earth bis(trifluoromethanesulfonimide) additives for efficient and stable perovskite solar cells. Nano Energy 69, 104412 (2020). https://doi.org/10.1016/j.nanoen.2019.104412

173. Li, Z., Wu, J., Liu, X., Zhu, Q., Yang, Y., Dou, Y., Du, Y., Zhang, X., Chen, Q., Sun, W., Lin, J.Y.: Highly efficient and stable perovskite solar cells using thionyl chloride as a p-type dopant for spiro-OMeTAD. J. Alloys Compd. 847, 156500 (2020). https:// doi.org/10.1016/j.jallcom.2020.156500

174. Hu, L., Li, S., Zhang, L., Liu, Y., Zhang, C., Wu, Y., Sun, Q., Cui, Y., Zhu, F., Hao, Y., Wu, Y.C.: Unravelling the role of C60 derivatives as additives into active layer for achieving high-efficiency planar perovskite solar cells. Carbon N. Y. 167, 160-168 (2020). https://doi.org/10.1016/j.carbon.2020.05.079

175. Wang, H., Zhang, F., Li, Z., Zhang, J., Lian, J., Song, J., Qu, J., Wong, W.Y.: Naphthalene imide dimer as interface engineering material: an efficient strategy for achieving high-performance perovskite solar cells. Chem. Eng. J. 395, 125062 (2020). https:// doi.org/10.1016/j.cej.2020.125062

176. Chen, W., Shi, Y., Wang, Y., Feng, X., Djurišić, A.B., Woo, H.Y., Guo, X., He, Z.: N-type conjugated polymer as efficient electron transport layer for planar inverted perovskite solar cells with power conversion efficiency of 2086\%. Nano Energy 68, 4363 (2020). https://doi.org/10.1016/j.nanoen.2019.104363

177. Lee, S., Lee, J., Park, H., Choi, J., Baac, H.W., Park, S., Park, H.J.: Defect-passivating organic/inorganic bicomponent holetransport layer for high efficiency metal-halide perovskite device. ACS Appl. Mater. Interfaces. 12, 40310-40317 (2020). https:// doi.org/10.1021/acsami.0c09784

178. Lee, J., Kim, G.W., Kim, M., Park, S.A., Park, T.: Nonaromatic green-solvent-processable, dopant-free, and lead-capturable hole transport polymers in perovskite solar cells with high efficiency. Adv. Energy Mater. 10, 1902662 (2020). https://doi.org/10.1002/ aenm.201902662

179. Wali, Q., Iqbal, Y., Pal, B., Lowe, A., Jose, R.: Tin oxide as an emerging electron transport medium in perovskite solar cells. Sol. Energy Mater. Sol. Cells. 179, 102-117 (2018). https://doi. org/10.1016/j.solmat.2018.02.007

180. Gra, C., Zakeeruddin, S.M.: Recent trends in mesoscopic solar cells based on molecular and nanopigment light harvesters. Mater. Today. 16, 11-18 (2013)

181. Zhang, F., Ma, W., Guo, H., Zhao, Y., Shan, X., Jin, K., Tian, H., Zhao, Q., Yu, D., Lu, X., Lu, G., Meng, S.: Interfacial oxygen vacancies as a potential cause of hysteresis in perovskite solar cells. Chem. Mater. 28, 802-812 (2016). https://doi.org/10.1021/ acs.chemmater.5b04019
182. Li, H., Li, D., Zhao, W., Yuan, S., Liu, Z., Wang, D., Liu, S.: $\mathrm{NaCl}$-assisted defect passivation in the bulk and surface of $\mathrm{TiO}_{2}$ enhancing efficiency and stability of planar perovskite solar cells. J. Power Sources. 448, 227586 (2020). https://doi.org/10.1016/j. jpowsour.2019.227586

183. Sun, H., Xie, D., Song, Z., Liang, C., Xu, L., Qu, X., Yao, Y., Li, D., Zhai, H., Zheng, K., Cui, C., Zhao, Y.: Interface defects passivation and conductivity improvement in planar perovskite solar cells using $\mathrm{Na}_{2} \mathrm{~S}$-doped compact $\mathrm{TiO}_{2}$ electron transport layers. ACS Appl. Mater. Interfaces. 12, 22853-22861 (2020). https://doi.org/10.1021/acsami.0c03180

184. Wang, T., Xie, M., Abbasi, S., Cheng, Z., Liu, H., Shen, W.: High efficiency perovskite solar cells with tailorable surface wettability by surfactant. J. Power Sources. 448, 227584 (2020). https:// doi.org/10.1016/j.jpowsour.2019.227584

185. Huang, S.H., Tian, K.Y., Huang, H.C., Li, C.F., Chu, W.C., Lee, K.M., Lee, K.M., Huang, Y.C., Su, W.F.: Controlling the morphology and interface of the perovskite layer for scalable highefficiency solar cells fabricated using green solvents and blade coating in an ambient environment. ACS Appl. Mater. Interfaces. 12, 26041-26049 (2020). https://doi.org/10.1021/acsami.0c062 11

186. Meng, L., Wei, Q., Yang, Z., Yang, D., Feng, J., Ren, X., Liu, Y., Liu, S.: (Frank): Improved perovskite solar cell efficiency by tuning the colloidal size and free ion concentration in precursor solution using formic acid additive. J. Energy Chem. 41, 43-51 (2020). https://doi.org/10.1016/j.jechem.2019.04.019

187. Koo, D., Cho, Y., Kim, U., Jeong, G., Lee, J., Seo, J., Yang, C., Park, H.: High-performance inverted perovskite solar cells with operational stability via n-type small molecule additive-assisted defect passivation. Adv. Energy Mater. 2001920 (2020). https:// doi.org/10.1002/aenm.202001920

188. Garai, R., Afroz, M.A., Gupta, R.K., Iyer, P.K.: Efficient trap passivation of MAPbI3 via multifunctional anchoring for highperformance and stable perovskite solar cells. Adv. Sustain. Syst. 4, 2000078 (2020). https://doi.org/10.1002/adsu.202000078

189. Guan, L., Zheng, Z., Guo, Y.: Enhanced hole transport in benzoic acid doped spiro-OMeTAD composite layer with intergrowing benzoate phase for perovskite solar cells. J. Alloys Compd. 832, 154991 (2020). https://doi.org/10.1016/j.jallcom.2020.154991

190. Chen, J., Kim, S.G., Ren, X., Jung, H.S., Park, N.G.: Effect of bidentate and tridentate additives on the photovoltaic performance and stability of perovskite solar cells. J. Mater. Chem. A. 7, 4977-4987 (2019). https://doi.org/10.1039/c8ta11977e

191. Han, T.H., Lee, J.W., Choi, C., Tan, S., Lee, C., Zhao, Y., Dai, Z., De Marco, N., Lee, S.J., Bae, S.H., Yuan, Y., Lee, H.M., Huang, Y., Yang, Y.: Perovskite-polymer composite crosslinker approach for highly-stable and efficient perovskite solar cells. Nat. Commun. 10, 1-10 (2019). https://doi.org/10.1038/ s41467-019-08455-Z

192. Ma, Y., Cheng, Y., Xu, X., Li, M., Zhang, C., Cheung, S.H., Zeng, Z., Shen, D., Xie, Y.M., Chiu, K.L., Lin, F., So, S.K., Lee, C.S., Tsang, S.W.: Suppressing ion migration across perovskite grain boundaries by polymer additives. Adv. Funct. Mater. 2006802 (2020). https://doi.org/10.1002/adfm.202006802

193. Bai, S., Da, P., Li, C., Wang, Z., Yuan, Z., Fu, F., Kawecki, M., Liu, X., Sakai, N., Wang, J.T.W., Huettner, S., Buecheler, S., Fahlman, M., Gao, F., Snaith, H.J.: Planar perovskite solar cells with long-term stability using ionic liquid additives. Nature 571, 245-250 (2019). https://doi.org/10.1038/s41586-019-1357-2

194. Mohammed, M.K.A.: $21.4 \%$ efficiency of perovskite solar cells using BMImI additive in the lead iodide precursor based on carbon nanotubes/ $\mathrm{TiO}_{2}$ electron transfer layer. Ceram. Int. 46, 27647-27654 (2020). https://doi.org/10.1016/j.ceramint.2020. 07.260 
195. Zhang, B., Fu, W., Meng, X., Runa, A., Su, P., Yang, H.: Improved crystallization of perovskite films using $\mathrm{PbTiO}_{3}$-decorated mesoporous scaffold layers for high stable carbon-counter-electrode solar cells. Org. Electron. 69, 164-173 (2019). https://doi.org/10.1016/j.orgel.2019.03.022

196. Jiang, L.L., Wang, Z.K., Li, M., Li, C.H., Fang, P.F., Liao, L.S.: Flower-like MoS 2 nanocrystals: A powerful sorbent of $\mathrm{Li}^{+}$in the
Spiro-OMeTAD layer for highly efficient and stable perovskite solar cells. J. Mater. Chem. A. 7, 3655-3663 (2019). https://doi. org/10.1039/c8ta11800k

Publisher's Note Springer Nature remains neutral with regard to jurisdictional claims in published maps and institutional affiliations. 